\title{
Forcing of the Upper-Tropospheric Monsoon Anticyclones
}

\author{
LeONG WAi SiU AND KenNeth P. BOWMAN \\ Department of Atmospheric Sciences, Texas A\&M University, College Station, Texas
}

(Manuscript received 19 November 2018, in final form 2 April 2019)

\begin{abstract}
During the boreal warm season (May-September), the circulation in the upper troposphere and lower stratosphere is dominated by two large anticyclones: the Asian monsoon anticyclone (AMA) and North American monsoon anticyclone (NAMA). The existence of the AMA has long been linked to Asian monsoon precipitation using the Matsuno-Gill framework, but the origin of the NAMA has not been clearly understood. Here the forcing mechanisms of the NAMA are investigated using a simplified dry general circulation model. The simulated anticyclones are in good agreement with observations when the model is forced by a zonally symmetric meridional temperature gradient plus a realistic geographical distribution of heating based on observed tropical and subtropical precipitation in the Northern Hemisphere. Model experiments show that the AMA and NAMA are largely independent of one another, and the NAMA is not a downstream response to the Asian monsoon. The primary forcing of the NAMA is precipitation in the longitude sector between $60^{\circ}$ and $120^{\circ} \mathrm{W}$, with the largest contribution coming from the subtropical latitudes within that sector. Experiments with idealized regional heating distributions reveal that the extratropical response to tropical and subtropical precipitation depends approximately linearly on the magnitude of the forcing but nonlinearly on its latitude. The AMA is stronger than the NAMA, primarily because precipitation in the subtropics over Asia is much heavier than at similar latitudes in the Western Hemisphere.
\end{abstract}

\section{Introduction}

Traditionally, monsoon refers to the seasonal reversal of the prevailing surface winds in the tropics (Gadgil 2003). Monsoon regions are distinct from the midlatitude and polar regions by having two seasons, one dry and the other wet. While the winter season is characterized by cool and dry air blowing from the continent, during summer, moist tropical maritime air moves onshore, bringing abundant rainfall to monsoon regions (Webster et al. 1998). The enormous amount of latent heat released by monsoon precipitation accounts for a large fraction of the total diabatic heating in the tropics (Yanai et al. 1973). This latent heating is important for driving mesoscale convective systems as well as largescale tropical circulations (Gill 1982; Holton 2004).

Figure 1 shows the climatological July geopotential height $Z$ at $150 \mathrm{hPa}$ from the European Centre for Medium-Range Weather Forecasts (ECMWF) interim reanalysis (ERA-Interim) (Dee et al. 2011). During the boreal warm season, the circulation of the upper

Corresponding author: Leong Wai Siu, chris.siu@tamu.edu troposphere and lower stratosphere (UTLS) is dominated by anticyclones over Asia and North America.

The Asian monsoon anticyclone (AMA), also known as the South Asian high, is centered at $\sim 30^{\circ} \mathrm{N}, \sim 70^{\circ} \mathrm{E}$ and is bounded by the subtropical westerly jet to the north and the tropical easterly jet to the south (Dethof et al. 1999). The onset of the AMA is typically in midMay. At its peak strength in July, the anticyclone extends over the entire Eastern Hemisphere (EH). The AMA begins weakening in September and typically disappears in October.

The North American monsoon anticyclone (NAMA), also known as the Mexican high, is located near $30^{\circ} \mathrm{N}$, $110^{\circ} \mathrm{W}$, but the circulation is not as strong and persistent as its Asian counterpart (Dunkerton 1995; Chen 2003). The NAMA emerges in late May off the Pacific coast of Central America, near the eastern Pacific intertropical convergence zone (ITCZ). It then moves northward along the Pacific coast of Mexico until it is centered near northwestern Mexico and the southwestern United States (Douglas et al. 1993). The circulation enters its mature phase in July and August and gradually decays from late September (Vera et al. 2006). 


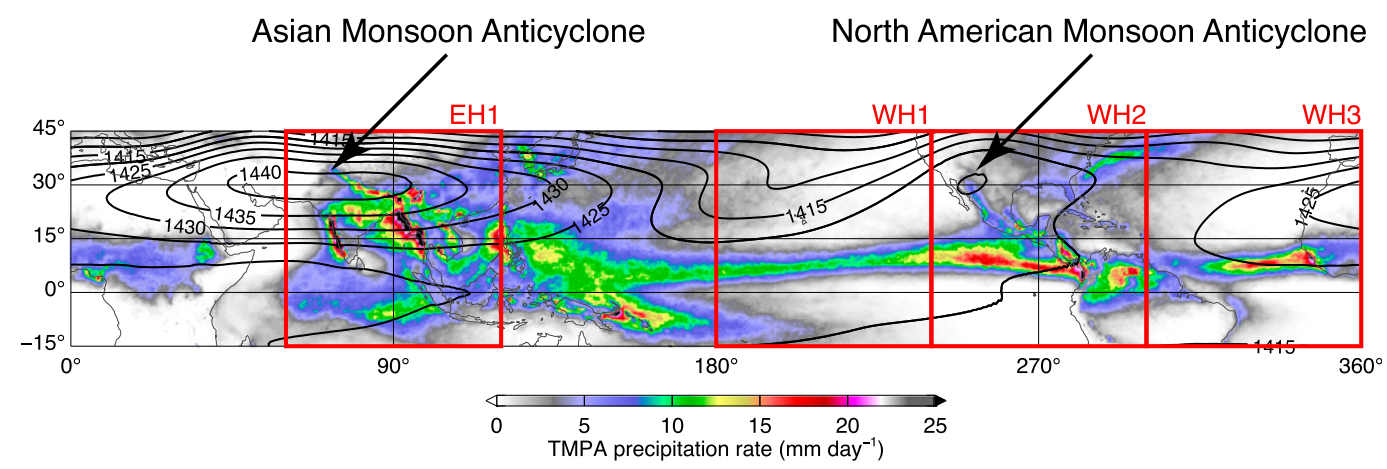

FIG. 1. TMPA climatological July precipitation rate $R$ (color) and ERA-Interim climatological July geopotential height $Z$ at $150 \mathrm{hPa}$ (contours; interval: $5 \mathrm{dam}$ ). The Asian and North American monsoon anticyclones are labeled and indicated by arrows. Four longitude sectors (EH1, WH1, WH2, WH3) of equal size are labeled and outlined in red. The longitudinal-mean precipitation of these sectors is examined in Fig. 6.

The AMA has long been viewed as, to first order, a response to the latent heat of condensation released by tropical and subtropical precipitation in the Eastern Hemisphere (e.g., Webster 1972; Gill 1980; Phlips and Gill 1987; Hoskins and Rodwell 1995). Gill (1980) extended the study of Matsuno (1966) and investigated the steady-state response of the linearized shallowwater equations on an equatorial $\beta$ plane in a resting atmosphere forced by simple heating distributions. The upper-tropospheric AMA can be considered as a westward-propagating Rossby wave response to tropical heat sources. To the east of the heat sources, an eastward-propagating Kelvin wave response is also excited. The strength of the steady-state Rossby wave response is governed by the linear inviscid vorticity equation or so-called the Sverdrup balance (Vallis 2017), which can be written as

$$
\beta v=-f(\nabla \cdot \mathbf{v})
$$

where $\mathbf{v}=(u, v)$ is the horizontal wind velocity vector, $f$ is the Coriolis parameter, and $\beta=\partial f / \partial y$ is the meridional gradient of $f$ at a given latitude. Note that the strength of the Gill-type response (1) is proportional to both the Coriolis parameter $f$, which is a function of latitude, and the divergence of the horizontal wind $\nabla \cdot \mathbf{v}$, which is proportional to the magnitude of the heating. Figure 1 also shows the climatological July precipitation from the National Aeronautics and Space Administration (NASA) Tropical Rainfall Measuring Mission (TRMM) Multisatellite Precipitation Analysis (TMPA; also referred to as 3B42) (Huffman et al. 2007). There are several regions of heavy precipitation in the Eastern Hemisphere: on the western coast of India, on the eastern side of the Bay of Bengal, over the northern part of the Philippines, and along the Himalayan front. Regions of less intense precipitation also cover a large part of the equatorial western Pacific. Schumacher et al. (2004) simulated a reasonable quasi-steady-state response of the AMA at $250 \mathrm{hPa}$ using a simplified general circulation model (GCM) forced by a TMPA-derived three-dimensional latent heating distribution. The Gilltype response was also used to explain the existence of the upper-tropospheric anticyclones over northwestern Australia during El Niño Modoki events (Taschetto et al. 2010) and over west-central South America during the austral warm season (Lenters and Cook 1997).

The origin of the upper-tropospheric NAMA circulation, however, is not clear. There are a number of studies on the spatial and temporal variations of precipitation in the North American monsoon (NAM) region, including Mexico and the United States (e.g., Douglas et al. 1993; Adams and Comrie 1997; Barlow et al. 1998; Higgins et al. 1997, 1998, 1999). Higgins et al. (1997, 1998) showed that during July and August the strength of the NAMA is related to the amount of precipitation in Arizona and New Mexico. Stensrud (2013) demonstrated the importance of diabatic heating in simulating the NAMA using a mesoscale numerical model. Chao and Chen (2001) asserted that land-sea contrasts and orography are important for simulating the North American monsoon. Other thermal forcings may also be important. The heaviest North American monsoon precipitation is located along the Sierra Madre Occidental in northwestern Mexico; however, the heaviest precipitation in the western Hemisphere $(\mathrm{WH})$ falls in the equatorial Pacific and Atlantic ITCZs, Central America, and the northern part of South America (Fig. 1). Given its magnitude and proximity, the ITCZ precipitation may contribute to the formation of the NAMA. In addition, heat sources in the Asia monsoon region may play a role through downstream wave effects. Chen et al. (2001) showed that in a linear, quasigeostrophic model the subtropical anticyclones in the lower 
troposphere over the North Pacific and the North Atlantic are a remote response to the Asian heat sources. Jiang and Lau (2008) showed that intraseasonal variability of the North American monsoon is associated with convective activity in the subtropical western North Pacific via a trans-Pacific wave train.

The fundamental dynamics of the NAMA may be a Matsuno-Gill-type response, but much is not understood about the origin and dynamics of the anticyclone and the contributions of heating from different regions. In this paper, we investigate whether the NAMA is a response to the diabatic heating from the Asian monsoon region, the North American monsoon region, the ITCZ, or a combination thereof. Our approach is through running numerical experiments with a simplified dry GCM dynamical core forced by observed and idealized heating distributions.

\section{Data}

\section{a. Atmospheric reanalysis}

To provide an observational foundation for the numerical experiments, we use 39 years (1979-2017) of the ERA-Interim product (ECMWF 2009). Data files are obtained from the Research Data Archive (RDA) at the National Center for Atmospheric Research (NCAR). The ERA-Interim system has a T255 spectral resolution and the corresponding reduced N128 Gaussian grid has a horizontal grid spacing of $\sim 0.7^{\circ} \times \sim 0.7^{\circ}(\sim 80 \mathrm{~km} \times$ $\sim 80 \mathrm{~km})$. Analyses are available at 6 -h intervals. For this study we use data on 37 unevenly spaced pressure levels. The topmost pressure level is $1 \mathrm{hPa}$. Monthly averages are computed as a simple arithmetic average of the 6-hourly data. Climatological monthly averages are computed in a similar manner from the monthly averages.

\section{b. Precipitation data}

To prescribe the horizontal latent heating distribution, which is used to specify diabatic heating rates in the GCM, we use 19 years (1998-2016) of 3-hourly TMPA, version 7, precipitation analyses (Tropical Rainfall Measuring Mission 2011; Huffman and Bolvin 2017). The TMPA has a horizontal grid spacing of $0.25^{\circ} \times 0.25^{\circ}$ over the latitude band from $50^{\circ} \mathrm{S}$ to $50^{\circ} \mathrm{N}$. Monthly averages are computed as a simple arithmetic average of the 3-hourly data. Climatological monthly averages are computed in a similar manner from the monthly averages.

\section{Simplified GCM}

\section{a. Dynamical core}

We use the dry Eulerian spectral dynamical core of the NCAR Community Atmosphere Model (CAM), version 5.4, which is the atmospheric component of the Community Earth System Model (CESM). The dynamical core solves the hydrostatic primitive equations formulated in vorticity-divergence form on a hybrid sigma-pressure $(\sigma-p)$, or $\eta$ coordinate, using a spectral transform method in the horizontal, a finite difference method in the vertical, and a semi-implicit leapfrog scheme for time integration (Neale et al. 2012). The model has no topography or moisture. A linear harmonic $\nabla^{2}$ diffusion is used in the top three model levels to absorb vertically propagating planetary wave energy and a linear biharmonic $\nabla^{4}$ diffusion is used in all other levels for subgrid-scale dissipation. Monthly averages and 6-hourly instantaneous model outputs are archived for offline calculations. Model variables are interpolated to the ERA-Interim pressure levels when necessary.

\section{b. Idealized physics package}

One of the goals of version 2 of the CESM is to support simpler model configurations. As a result, CAM 5.4 offers an idealized physics configuration based on Held and Suarez (1994, hereafter HS94) as an alternative to full physics parameterizations. While the default HS94 simulation resembles the general circulation of the atmosphere in equinoctial conditions, the height of the climatological tropical tropopause differs somewhat from observations (340-350 vs 360-380 K) and the tropical lapse rate in radiative equilibrium follows the dry adiabatic lapse rate rather than the moist one (Tandon et al. 2011). Since this study is focused on the tropical UTLS region, we adopt an HS94-like physics package from Schneider (2004) and Schneider and Walker (2006, hereafter SW06) to better reproduce the tropical circulation. The two Schneider configurations differ slightly in their treatment of the moist adiabatic profile; therefore, we make reference only to the SW06 configuration from here on. Values of selected parameters of the idealized physics package are given in Table 1.

\section{1) SURFACE DRAG}

A quadratic drag is applied to the horizontal wind within the planetary boundary layer. The depth of the boundary layer extends to $\eta_{\mathrm{BL}}=0.85$. The strength of the drag depends on the frictional wavenumber at the surface $k_{d}^{0}$.

\section{2) RADIATIVE PROCESSES}

Newtonian relaxation is used to represent radiative forcing and moist convection in a semigray atmosphere. 
TABLE 1. Selected parameters of the idealized physics package described in section 3. Parameters related to the horizontal distribution of thermal forcing are summarized in Tables 2 and 3.

\begin{tabular}{lcc}
\hline \hline \multicolumn{1}{c}{ Description } & Symbol & Value \\
\hline Average radius of Earth & $a$ & $6.37122 \times 10^{6} \mathrm{~m}$ \\
Acceleration of gravity & $g$ & $9.80616 \mathrm{~m} \mathrm{~s}^{-2}$ \\
Specific heat of dry air at constant pressure & $c_{p}$ & $1004.64 \mathrm{~J} \mathrm{~kg}^{-1} \mathrm{~K}^{-1}$ \\
Latent heat of condensation of water & $L_{v}$ & $2.5 \times 10^{6} \mathrm{~J} \mathrm{~kg}^{-1}$ \\
Density of water & $\rho$ & $1000 \mathrm{~kg} \mathrm{~m}^{-3}$ \\
Frictional wavenumber near the surface & $k_{d}^{0}$ & $0.7 \times 10^{-5} \mathrm{~m}^{-1}$ \\
Extent of boundary layer & $\eta_{\mathrm{BL}}$ & 0.85 \\
Equatorial temperature & $T_{\text {equator }}^{r}$ & $345 \mathrm{~K}$ \\
Minimum radiative equilibrium temperature & $T_{\text {min }}^{r}$ & $200 \mathrm{~K}$ \\
Pole-to-equator temperature difference in equinoctial conditions & $\Delta_{h}$ & $30 \mathrm{~K}$ \\
Latitude of maximum surface radiative equilibrium temperature & $\phi_{0}^{r}$ & $20^{\circ} \mathrm{N}$ \\
Scale-height ratio & $\alpha$ & 3.5 \\
Radiative relaxation time scale in the free atmosphere & $\tau_{a}$ & $55 \mathrm{days}$ \\
Radiative relaxation time scale near surface & $\tau_{s}$ & $7 \mathrm{days}$ \\
Convective relaxation time scale & $\tau_{c}$ & $4 \mathrm{days}$ \\
Dry adiabatic lapse rate & $\Gamma_{d}$ & $9.8 \mathrm{~K} \mathrm{~km}$ \\
Rescaling factor of pseudoadiabatic lapse rate & $\gamma$ & 0.85 \\
Reference surface pressure & $p_{0}$ & $1000 \mathrm{hPa}$ \\
Top pressure level of thermal forcing & $p_{t}$ & $100 \mathrm{hPa}$ \\
Bottom pressure level of thermal forcing & $p_{b}$ & $A$ \\
Normalization factor of vertical distribution of thermal forcing & $B$ & $1000 \mathrm{hPa}$ \\
Shape parameter of vertical distribution of thermal forcing & & 1.570247 \\
\hline
\end{tabular}

Similar to Tandon et al. (2013), the prognostic equation for temperature $T$ is

$$
\begin{aligned}
\frac{\partial T}{\partial t}= & \cdots-\frac{T-T^{r}(\phi, p)}{\tau_{r}(\phi, \eta)}-\frac{T-T^{c}(\lambda, \phi, p, t)}{\tau_{c}} \\
& +Q_{\mathrm{LH}}(\lambda, \phi, p),
\end{aligned}
$$

where $\lambda, \phi, \eta, p$, and $t$ are longitude, latitude, hybrid vertical coordinate, pressure, and time; $T^{r}$ and $\tau_{r}$ are the radiative equilibrium temperature and relaxation time scale; $T^{c}$ and $\tau_{c}$ are the convective equilibrium temperature and relaxation time scale; and $Q_{\mathrm{LH}}$ is the external thermal forcing that represents latent heating.

The radiative heating $Q_{R}$ is parameterized as the first term on the right-hand side (rhs) of (2). First, the surface temperature at radiative equilibrium $T_{s}^{r}$ is prescribed as

$$
T_{s}^{r}(\phi)=T_{\text {equator }}^{r}-\Delta_{h}\left(\sin ^{2} \phi-2 \sin \phi_{0}^{r} \sin \phi\right),
$$

where $T_{\text {equator }}^{r}$ is the equatorial temperature, $\phi_{0}^{r}$ is the latitude of maximum surface radiative equilibrium temperature, and $\Delta_{h}$ is the pole-to-equator temperature difference under equinoctial conditions. Note that the form of $T_{s}^{r}$ is identical to Schneider and Bordoni (2008) and depends on latitude $\phi$ only. The optical thickness of the atmosphere at different latitudes is determined by the surface radiative equilibrium temperature $T_{s}^{r}$ and the minimum radiative equilibrium temperature at the top of atmosphere $T_{\min }^{r}$ as in SW06. Then the radiative equilibrium temperature $T^{r}$ can be computed by

$$
T^{r}(\phi, p)=T_{\min }^{r}\left[1+d_{0}(\phi)\left(\frac{p}{p_{0}}\right)^{\alpha}\right]^{1 / 4},
$$

where $T_{\min }^{r}=200 \mathrm{~K}, p_{0}=1000 \mathrm{hPa}$ is the reference surface pressure, $d_{0}$ is the optical thickness of the semigray atmosphere, and $\alpha$ is the scale-height ratio. The radiative equilibrium temperature $T^{r}$ at $1000 \mathrm{hPa}$ of this form is matched up with the surface radiative equilibrium temperature $T_{s}^{r}$.

The temperature field $T$ is relaxed toward the zonally symmetric radiative equilibrium temperature profile $T^{r}$ with a radiative time scale $\tau_{r}$, which depends on both latitude and vertical level as in SW06. In this study, $\tau_{r}$ is equal to $\tau_{a}=55$ days in the free atmosphere and decreases linearly within the boundary layer to $\tau_{s}=7$ days near the surface.

\section{3) Convective adjustment}

The convective heating $Q_{C}$ is parameterized as the second term on the rhs of (2) to represent convective adjustment. This term is absent in the original HS94 configuration, in which the adjustment is implicitly 
done via a judiciously chosen equilibrium radiative temperature profile. The radiative equilibrium temperature of the SW06 configuration, however, is statically unstable for most of the lower troposphere, which necessitates the inclusion of a simple dry convection scheme. This scheme relaxes the temperature field $T$ toward the convective equilibrium temperature $T^{c}$ on the convective time scale $\tau_{c}$ only when a layer is statically unstable in comparison with the convective lapse rate and has a positive convective available potential energy. The convective lapse rate is $\gamma \Gamma_{d}$, where $\Gamma_{d}=$ $9.8 \mathrm{~K} \mathrm{~km}^{-1}$ is the dry adiabatic lapse rate, and $\gamma=0.85$ is a nondimensional scale factor to represent the effect of moist convection.

\section{4) THERMAL FORCING}

The latent heating $Q_{\mathrm{LH}}$ is the last term on the rhs of (2). It represents an imposed three-dimensional thermal forcing due to latent heat of condensation, which is expressed as

$$
Q_{\mathrm{LH}}(\lambda, \phi, p)=Q_{0} Q_{h}(\lambda, \phi) Q_{v}(p),
$$

where $Q_{0}$ is a dimensional parameter $\left(\mathrm{K} \mathrm{day}^{-1}\right)$ that determines the magnitude of the thermal forcing; $Q_{h}$ and $Q_{v}$ are the horizontal and vertical distributions of the thermal forcing, respectively, and are dimensionless.
Note that $T^{r}$ and $Q_{\mathrm{LH}}$ have no time dependence in (2) and (5), respectively; there are, therefore, no diurnal or seasonal cycles.

In this study, the horizontal distribution of the thermal forcing $Q_{h}$ is either derived from the observed TMPA precipitation rate $R$ or specified as idealized distributions. For the former, the observed precipitation field, given a specified range of longitude and latitude, is first area averaged from the TMPA grid to the model grid, taking care to preserve the total amount of precipitation. Then $Q_{h}$ is obtained by normalizing the area-averaged precipitation field.

For the latter, two idealized horizontal precipitation distributions are being used. The first one is a zonally elongated thermal forcing, which resembles the appearance of the Pacific ITCZ and is specified in (6), where $\lambda_{0}$ and $\phi_{0}$ are the center longitude and latitude of the forcing; $\Delta \lambda$ and $\Delta \phi$ are the zonal and meridional extents of the forcing. Note that within the forcing region the strength of the forcing is uniform in the zonal direction.

The second is a more compact regional forcing given by (7).

The vertical distribution of the thermal forcing $Q_{v}$ is identical to DeMaria (1985), which is prescribed in (8),

$$
\begin{aligned}
& Q_{h}(\lambda, \phi)=\left\{\begin{array}{cl}
\cos ^{2}\left[\left(\frac{\phi-\phi_{0}}{\Delta \phi}\right) \pi\right], & \text { if }\left|\lambda-\lambda_{0}\right| \leq \frac{\Delta \lambda}{2} \quad \text { and } \quad\left|\phi-\phi_{0}\right| \leq \frac{\Delta \phi}{2}, \\
0, & \text { elsewhere }
\end{array}\right. \\
& Q_{h}(\lambda, \phi)=\left\{\begin{array}{cl}
\cos \left[\left(\frac{\lambda-\lambda_{0}}{\Delta \lambda}\right) \pi\right] \cos ^{2}\left[\left(\frac{\phi-\phi_{0}}{\Delta \phi}\right) \pi\right], & \text { if }\left|\lambda-\lambda_{0}\right| \leq \frac{\Delta \lambda}{2} \quad \text { and }\left|\phi-\phi_{0}\right| \leq \frac{\Delta \phi}{2} \\
0, & \text { elsewhere }
\end{array}\right. \\
& Q_{v}(p)=\left\{\begin{array}{cl}
A \sin \left[\left(\frac{p-p_{t}}{p_{b}-p_{t}}\right) \pi\right] \exp \left[-B\left(\frac{p-p_{t}}{p_{b}-p_{t}}\right)\right], & \text { if } \quad p_{t} \leq p \leq p_{b} \\
0, & \text { elsewhere }
\end{array}\right.
\end{aligned}
$$

where $Q_{v}$ is a function of pressure; $p_{t}$ and $p_{b}$ are the top and bottom pressure levels of the forcing, respectively; $A$ is a dimensionless factor to normalize the range of $Q_{v}$ to be between 0 and 1 ; and $B$ is a constant to change the shape of $Q_{v}$. In this study, all numerical experiments use different horizontal distributions of thermal forcing $Q_{h}$ but the same vertical distribution $Q_{v}$.
The forcing magnitude parameter $Q_{0}$ is tuned through sensitivity experiments to produce the best possible simulation of the global circulation, with an emphasis on the amplitude and location of the tropical easterlies, subtropical westerlies, and monsoon anticyclones. To facilitate the comparison of latent heating between TMPA observations and model, we compute the global total latent heating $Q_{\text {total }}\left(\mathrm{J} \mathrm{day}^{-1}\right)$. The total amount of 
TABLE 2. Summary of the numerical experiments with thermal forcing based on the TMPA observations. The second column gives the model resolution. The third through fifth columns give the description, latitude range, and longitude range of the forcing, respectively. The last two columns give the maximum magnitude $Q_{0}$ and total amount $Q_{\text {total }}$ of the forcing, respectively. Information for TMPA observations is included for reference. All experiments use the same vertical distribution of thermal forcing (Table 1).

\begin{tabular}{|c|c|c|c|c|c|c|}
\hline Run & Resolution & Description & Latitude range & Longitude range & $Q_{0}\left(\mathrm{~K} \mathrm{day}^{-1}\right)$ & $Q_{\text {total }}\left(10^{19} \mathrm{~J}_{\text {day }^{-1}}\right)$ \\
\hline TMPA & - & Tropics and subtropics & $5^{\circ} \mathrm{S}-40^{\circ} \mathrm{N}$ & $180^{\circ} \mathrm{W}-180^{\circ} \mathrm{E}$ & - & 187.95 \\
\hline 1a & T42L30 & No forcing & - & - & 0.00 & 0.00 \\
\hline $1 b$ & T85L30 & No forcing & - & - & 0.00 & 0.00 \\
\hline $1 \mathrm{c}$ & T42L60 & No forcing & - & - & 0.00 & 0.00 \\
\hline $2 \mathrm{a}$ & T42L30 & Tropics and subtropics & $5^{\circ} \mathrm{S}-40^{\circ} \mathrm{N}$ & $180^{\circ} \mathrm{W}-180^{\circ} \mathrm{E}$ & 6.35 & 110.16 \\
\hline $2 b$ & T42L30 & EH tropics and subtropics & $5^{\circ} \mathrm{S}-40^{\circ} \mathrm{N}$ & $0^{\circ}-180^{\circ} \mathrm{E}$ & 6.35 & 66.66 \\
\hline $2 \mathrm{c}$ & T42L30 & WH tropics and subtropics & $5^{\circ} \mathrm{S}-40^{\circ} \mathrm{N}$ & $180^{\circ} \mathrm{W}-0^{\circ}$ & 4.87 & 43.50 \\
\hline $3 a$ & T42L30 & Central Pacific & $5^{\circ} \mathrm{S}-40^{\circ} \mathrm{N}$ & $180^{\circ}-120^{\circ} \mathrm{W}$ & 3.54 & 10.33 \\
\hline $3 b$ & T42L30 & NAM region and eastern Pacific & $5^{\circ} \mathrm{S}-40^{\circ} \mathrm{N}$ & $120^{\circ}-60^{\circ} \mathrm{W}$ & 4.87 & 21.97 \\
\hline $3 c$ & T42L30 & Atlantic & $5^{\circ} \mathrm{S}-40^{\circ} \mathrm{N}$ & $60^{\circ} \mathrm{W}-0^{\circ}$ & 4.58 & 11.20 \\
\hline $3 \mathrm{~d}$ & T42L30 & Tropical part of $3 a$ & $5^{\circ} \mathrm{S}-15^{\circ} \mathrm{N}$ & $180^{\circ}-120^{\circ} \mathrm{W}$ & 3.54 & 8.41 \\
\hline $3 e$ & T42L30 & Tropical part of $3 b$ & $5^{\circ} \mathrm{S}-15^{\circ} \mathrm{N}$ & $120^{\circ}-60^{\circ} \mathrm{W}$ & 4.87 & 13.54 \\
\hline $3 f$ & T42L30 & Tropical part of $3 c$ & $5^{\circ} \mathrm{S}-15^{\circ} \mathrm{N}$ & $60^{\circ} \mathrm{W}-0^{\circ}$ & 4.58 & 9.45 \\
\hline $3 g$ & T42L30 & Subtropical part of $3 \mathrm{a}$ & $15^{\circ}-40^{\circ} \mathrm{N}$ & $180^{\circ}-120^{\circ} \mathrm{W}$ & 0.71 & 1.91 \\
\hline $3 \mathrm{~h}$ & T42L30 & Subtropical part of $3 b$ & $15^{\circ}-40^{\circ} \mathrm{N}$ & $120^{\circ}-60^{\circ} \mathrm{W}$ & 2.81 & 8.43 \\
\hline $3 \mathrm{i}$ & T42L30 & Subtropical part of $3 c$ & $15^{\circ}-40^{\circ} \mathrm{N}$ & $60^{\circ} \mathrm{W}-0^{\circ}$ & 1.52 & 1.75 \\
\hline
\end{tabular}

latent heating from the observed precipitation rate is given by

$$
Q_{\text {total }}=\iint \rho L_{v} R(\lambda, \phi) a^{2} \cos \phi d \phi d \lambda,
$$

where $\rho$ is the density of water, $L_{v}$ is the latent heat of condensation of water, $R(\lambda, \phi)$ is the two-dimensional TMPA precipitation $\left(\mathrm{mday}^{-1}\right)$, and $a$ is the average radius of Earth.

Under the hydrostatic assumption, the total amount of latent heating in the model is defined as

$$
Q_{\mathrm{total}}=\iiint c_{p} Q_{\mathrm{LH}}(\lambda, \phi, p) a^{2} \cos \phi d \phi d \lambda \frac{d p}{g},
$$

where $c_{p}$ is the specific heat of dry air at constant pressure, $Q_{\mathrm{LH}}(\lambda, \phi, p)$ is the three-dimensional thermal forcing computed from (5), and $g$ is the acceleration of gravity.

\section{c. Experimental design}

To evaluate the contribution of latent heating in different parts of the tropics and Northern Hemisphere subtropics to driving the NAMA, we carry out numerical experiments using the simplified GCM. The parameters of the realistic and idealized heating experiments are summarized in Tables 2 and 3, respectively. The control experiments (runs 1a-1c) have zero forcing $\left(Q_{0}=0 \mathrm{~K} \mathrm{day}^{-1}\right)$. The first set of perturbed experiments (runs 2a-2c) uses realistic heating distributions derived from the TMPA climatological July precipitation rate to investigate the contribution of the global and hemispheric heating to driving the NAMA. The second set of perturbed experiments (runs 3a-3i) further analyzes the contribution of different regions in the Western Hemisphere to the NAMA response. Additional experiments 4-6 examine the response to the idealized heating distributions specified by (6) and (7). The last set of experiment is used to test the model sensitivity to both horizontal resolution (runs $7 \mathrm{a}-7 \mathrm{e}$ ) and vertical resolution (runs $7 \mathrm{f}-7 \mathrm{j}$ ).

Most of the numerical experiments are integrated for 600 days at T42L30 resolution, denoting a triangular truncation of the spherical harmonic series at wavenumber $42\left(\sim 2.8^{\circ}\right.$ latitude $\times \sim 2.8^{\circ}$ longitude on a Gaussian grid), and 30 evenly spaced vertical levels between $\eta \approx 0.9833$ and 0.0167 . To test the model sensitivity, several experiments are repeated at T85 horizontal resolution $\left(\sim 1.4^{\circ} \times \sim 1.4^{\circ}\right)$ while other experiments use an L60 vertical resolution (60 evenly spaced vertical levels between $\eta \approx 0.9917$ and 0.0083 ). The model is initialized with a resting isothermal atmosphere at $250 \mathrm{~K}$. To satisfy the numerical stability criterion, the model time step size is set to 900 (450) s for T42 (T85) experiments. To prevent energy accumulation at small scales, the biharmonic dissipation coefficient is set to $1.17 \times 10^{16}\left(7.14 \times 10^{14}\right) \mathrm{m}^{4} \mathrm{~s}^{-1}$ for T42 (T85) experiments, with a damping time scale of $12 \mathrm{~h}$ at the smallest wavelength (MacVean 1983).

The zonally symmetric basic state temperature profile $T^{r}$ is the same in all experiments, as shown in Figs. 2a and 2b (cf. Fig. 1 of HS94 and Figs. 1 and 3 of Schneider 2004). The asymmetry constant $\phi_{0}^{r}=20^{\circ} \mathrm{N}$ mimics the boreal atmosphere near the summer solstice. Inspection 
TABLE 3. Summary of the numerical experiments with idealized zonally elongated and compact regional thermal forcings. Second column gives the model resolution. Third through seventh columns give the description, center longitude $\lambda_{0}$, zonal extent $\Delta \lambda$, center latitude $\phi_{0}$, and meridional extent $\Delta \phi$ of the forcing, respectively. Last two columns give the maximum magnitude $Q_{0}$ and total amount $Q_{\text {total }}$ of the forcing, respectively. All experiments use the same vertical distribution of thermal forcing (Table 1).

\begin{tabular}{lcccccccc}
\hline \hline Run & Resolution & Description & $\lambda_{0}\left({ }^{\circ} \mathrm{W}\right)$ & $\Delta \lambda\left({ }^{\circ}\right)$ & $\phi_{0}\left({ }^{\circ} \mathrm{N}\right)$ & $\Delta \phi\left({ }^{\circ}\right)$ & $Q_{0}\left(\mathrm{~K} \mathrm{day}^{-1}\right)$ & $Q_{\text {total }}\left(10^{19} \mathrm{~J}\right.$ day \\
\end{tabular}

of time series of various model parameters shows that the transient response from the isothermal initial condition is negligible after about 300 days. Therefore, the first 300 days of each simulation is discarded as model spinup. The remaining 300 days, which are sampled four times per day, are used to compute circulation statistics. Figures $2 \mathrm{c}$ and $2 \mathrm{~d}$ show the resulting climatology from run 1a at T42L30 resolution. Compared to the basic state, the meridional gradient of the zonal-mean surface temperature is reduced because of the poleward and upward energy transport by baroclinic eddies (Schneider 2004).

Runs $1 \mathrm{~b}$ and $1 \mathrm{c}$, which are integrated at T85L30 and T42L60 resolution, respectively, produce a very similar climatology (not shown). Increasing horizontal resolution leads to a slightly stronger boreal (weaker austral) subtropical jet, a somewhat stronger winter Hadley cell, and a lower tropical temperature near the surface. Increasing vertical resolution results in slightly stronger subtropical jets in both hemispheres, a relatively
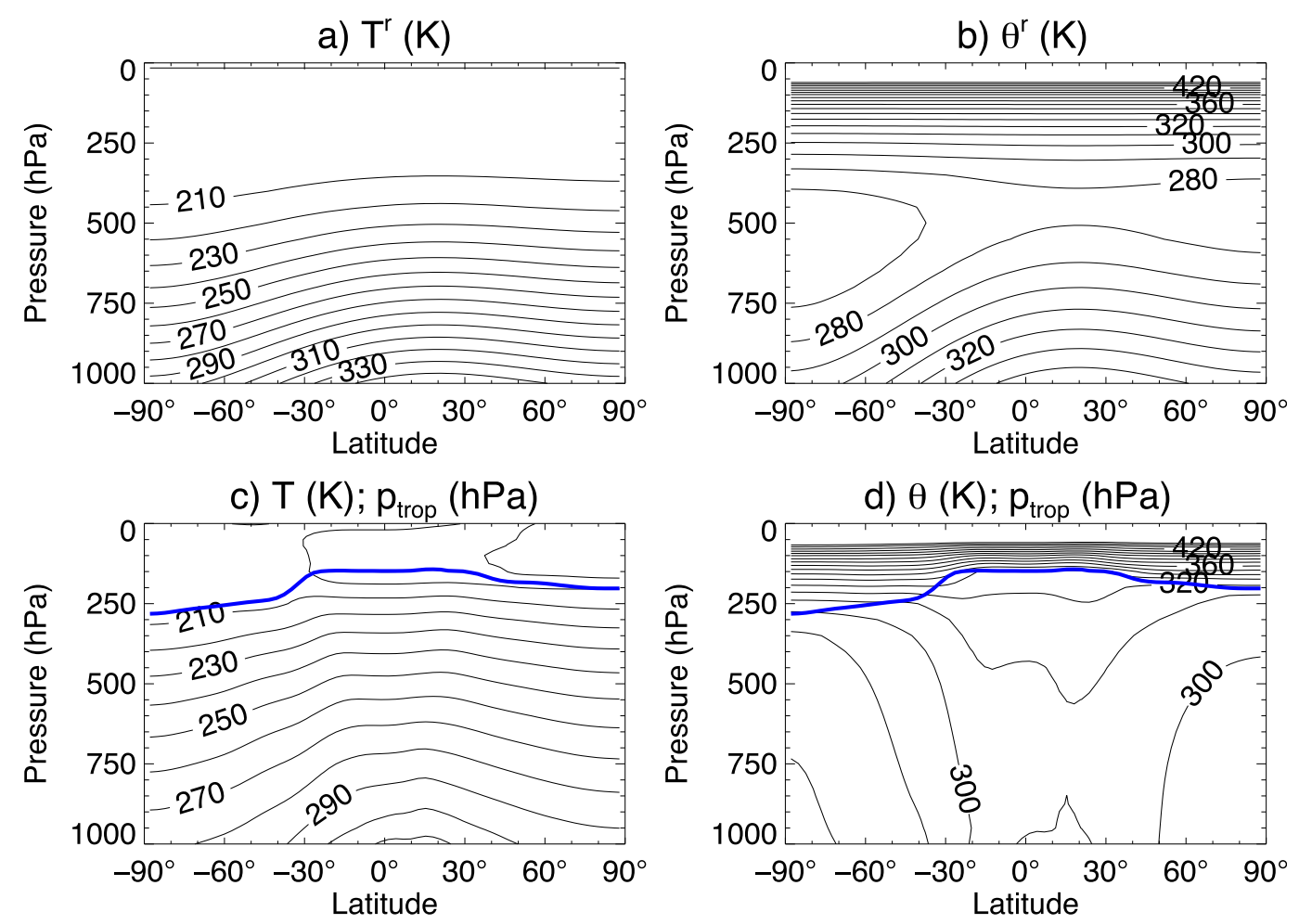

FIG. 2. (top) Basic state for all numerical experiments: (a) reference temperature $T^{r}$ and (b) reference potential temperature $\theta^{r}$. (bottom) Zonal-mean climatology of run 1a with no thermal forcing (control experiment for all simulations at T42L30 resolution): (c) temperature $T$ and (d) potential temperature $\theta$. The tropopause pressure $p_{\text {trop }}$ is shown in blue in (c) and (d). Contour intervals of all temperature fields are $10 \mathrm{~K}$. Contours of $\theta$ and $\theta^{r}$ above $450 \mathrm{~K}$ are omitted. 
stronger winter Hadley cell, and a rather lower temperature at the cold-point tropical tropopause.

\section{Results and discussions}

a. Response to the realistic forcing

\section{1) Model tuning}

To determine the major forcing regions of the NAMA, numerical experiments are carried out using realistic global and regional geographical distributions of latent heating derived from the TMPA precipitation data. A top-down approach is used to analyze the impacts of various regions on the upper-tropospheric circulation. The model is first subjectively tuned to produce a realistic zonal-mean state and reasonable representations of the AMA and NAMA when forced by latent heating throughout the tropics and subtropics (run 2a). The time-averaged model response to latent heating within selected regions is then examined.

Because of several significant simplifications in the model, including the absence of topography, land-sea contrast, and temporal variations of the heating, a perfect simulation is not expected. To produce the best possible simulation of the monsoon anticyclones, the principal tuning parameter for the basic state is the pole-to-equator temperature gradient $\Delta_{h}$, while the horizontal distribution $Q_{h}$, vertical distribution $Q_{v}$, and strength $Q_{0}$ of the thermal forcing also play important roles.

Preliminary experiments show that the subtropical jet strengthens when either the pole-to-equator temperature gradient or the total external thermal forcing increases. To include a representative geographical extent of the forcing region, but at the same time not make the jet too strong, we set $\Delta_{h}=30 \mathrm{~K}$ and limit the TMPAderived forcing to the zone from $5^{\circ} \mathrm{S}$ to $40^{\circ} \mathrm{N}$.

Preliminary experiments also show that the response of the anticyclones is not very sensitive to the vertical extent of the forcing, especially the bottom-level $p_{b}$, but the shape parameter of the vertical distribution $B$ does matter. The top and bottom levels of the forcing in the vertical direction are set to 100 and $1000 \mathrm{hPa}$, respectively, and a slightly top-heavy profile $(B=1)$ is used in (8). Although Barlow et al. (1998) computed the vertical heating profile over Mexico from two reanalyses and found that there are double maxima at 200 and $400 \mathrm{hPa}$, the current profile used over the whole domain has a single peak near $450 \mathrm{hPa}$.

Finally, the forcing magnitude parameter $Q_{0}$ of run 2a is adjusted to produce the best response. Within the forcing region, the total observed latent heat of condensation computed from (9) is approximately $188 \times$ $10^{19} \mathrm{~J} \mathrm{day}^{-1}$ (Table 2). The most realistic response is found for $Q_{0}=6.35 \mathrm{~K} \mathrm{day}^{-1}$, which corresponds to approximately $59 \%$ of the observed amount of latent heating computed from (10). Attempting to adjust the model by increasing $Q_{0}$ closer to $100 \%$ of the observed heating and decreasing $\Delta_{h}$ to compensate changes the general circulation in undesirable ways.

\section{2) Global heating}

The performance of the model when forced by heating in both the Eastern and Western Hemispheres (run 2a) is assessed through comparisons with the ERAInterim July climatology. Figure 3 shows selected timemean, zonal-mean fields. CAM temperatures are high near the surface, which is typical for a dry GCM without surface energy fluxes (Figs. 3a and 3b), but the discrepancy becomes smaller in the free troposphere (Fig. 3c). The model produces a reasonable structure for both summer and winter subtropical jets (Figs. 3d and $3 \mathrm{e}$ ), although the summer jet is somewhat strong compared to observations $\left(31.2\right.$ vs $\left.21.8 \mathrm{~m} \mathrm{~s}^{-1}\right)$. The tropical easterlies are also stronger in the model than in observations, but the difference is modest (Fig. 3f). The difference in jet strength can be attributed to a lack of other mechanisms of heat transport (Baker et al. 2017). The tropopause height in the deep tropics generally agrees well with observations. With a very weak stratospheric lapse rate (Fig. 2c), the polar-night jet is absent in this model.

Figures $4 \mathrm{a}$ and $4 \mathrm{~b}$ shows the observed and simulated geopotential height $Z$ (contours) for the reanalysis and run 2a, respectively; the thermal forcing distribution $Q_{\mathrm{LH}}$ (color) is also shown in Fig. 4b. Both quantities are plotted at $150 \mathrm{hPa}$. The simulation reproduces the size and magnitude of the anticyclones well compared to the reanalysis, although the center of the AMA is about $45^{\circ}$ east of its observed position. The longitudinal bias of the center of NAMA is much smaller than for the AMA. Besides the eastward bias, the AMA is more zonally elongated in the model, which may be due to a somewhat large radiative relaxation time scale $\tau_{r}$. The trough over the Pacific that separates the two anticyclones (near $150^{\circ} \mathrm{W}$ ) is weaker in the simulation but is still noticeable.

Figure 5 compares meridional and zonal vertical sections of the time-mean horizontal wind structure through the centers of the AMA and NAMA. Zonal averages of $u$ and meridional averages of $v$ are computed over $45^{\circ}$ sectors and $10^{\circ}$ zones, respectively. Note the shift in longitude for the zonal section of the AMA in Fig. 5d. For the AMA, the subtropical westerlies are stronger in the model, as expected from Fig. 3e, but the difference of strength in the tropical easterlies is small (Figs. 5a and 5c). The meridional wind in the AMA is slightly stronger in the model (Figs. 5b and 5d). 
ERA-Interim July climatology
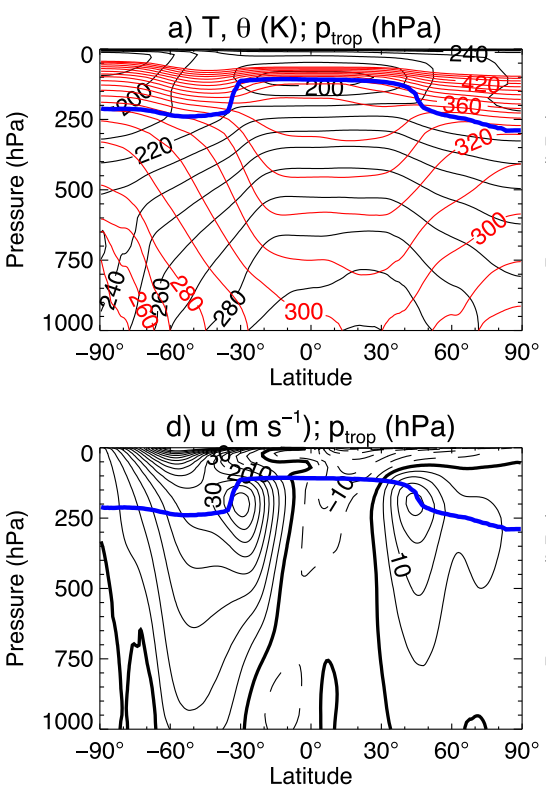

CAM run $2 a$
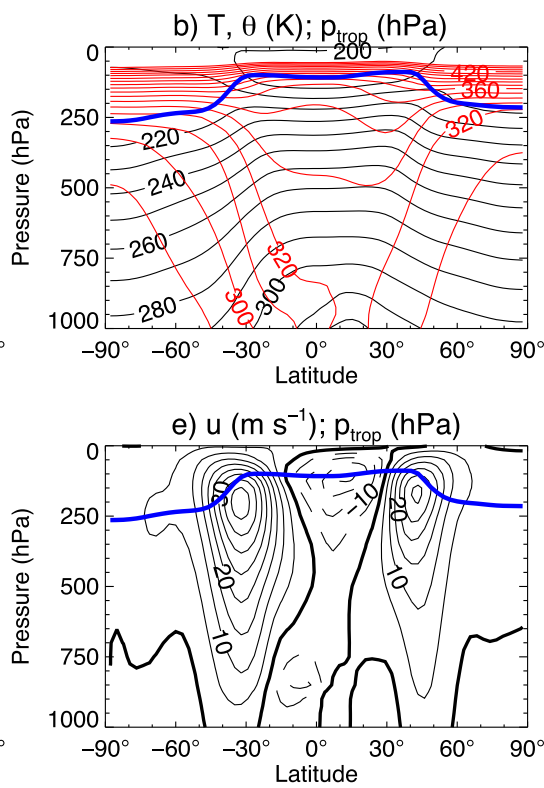

CAM minus ERA-Interim
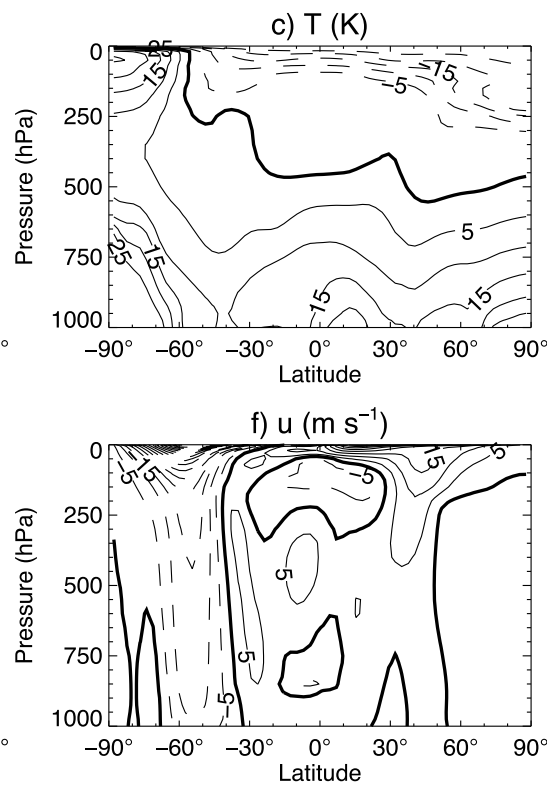

FIG. 3. Latitude-pressure cross sections of selected time-mean, zonal-mean fields. (left) ERA-Interim July climatology. (center) CAM run 2a. (right) Difference (CAM minus ERA-Interim). (a),(b) Temperature $T$ (black) and potential temperature $\theta$ (red). (c) Temperature $T$. (d)-(f) Zonal wind $u$. The tropopause pressure $p_{\text {trop }}$ (blue) is shown in the left and middle columns. Contour intervals of $T$ for (a) and (b) are $10 \mathrm{~K}$ and (c) are $5 \mathrm{~K}$. Contour intervals of $\theta$ and $u$ are $10 \mathrm{~K}$ and $5 \mathrm{~m} \mathrm{~s}^{-1}$, respectively. Negative values are dashed, and zero values of $T$ and $u$ are in bold contours. Contours of $\theta$ above $450 \mathrm{~K}$ are omitted.

The vertical extent of the AMA is between 300 and $50 \mathrm{hPa}$ and agrees well between the observations and simulation. For the NAMA, the simulation satisfactorily reproduces the magnitude and location of the subtropical jet (Figs. 5e and 5g). Contrary to the AMA, the meridional wind in the NAMA is slightly weaker in the model (Figs. $5 \mathrm{f}$ and $5 \mathrm{~h}$ ). Also the NAMA does not extend as high as the AMA. Overall the simplified GCM is capable of reproducing the major features of both anticyclones with realistic amplitudes when forced by the observed, time-averaged, geographical distribution of latent heating.

The diabatic heating from the physics package in (2) consists of the radiative heating $Q_{R}$, convective heating $Q_{C}$, and latent heating $Q_{\mathrm{LH}}$. The convective adjustment normally stabilizes the troposphere by transporting heat upward. Inside regions with abundant precipitation (e.g., monsoon regions), the heating is dominated by $Q_{R}$ and $Q_{\mathrm{LH}}$, and $Q_{C}$ is very small by comparison. Inside dry regions (e.g., the Sahara), $Q_{\mathrm{LH}}$ and $Q_{C}$ can have similar magnitudes but the total heating is still dominated by $Q_{R}$. Therefore, the overall contribution of convective heating within the forcing region is very small.

\section{3) HEMISPHERIC HEATING}

Experiment 2a provides the basis for analyzing the contributions to the forcing from individual geographical regions. The forcing is first divided into Eastern and Western Hemisphere contributions (Figs. 4c and 4d; runs $2 b$ and $2 c$ ). The total heating in run $2 a$ is equal to the sum of the heating in runs $2 b$ and $2 c$ (Table 2). The AMA is slightly weaker when the Western Hemisphere heating is removed (Fig. 4c). A deep trough is still distinct in the Pacific. Similarly, the NAMA is slightly weaker when the Eastern Hemisphere heating is removed (Fig. $4 d$ ). In runs $2 b$ and $2 c$ the westerlies are somewhat weaker than in run $2 \mathrm{a}$. These experiments demonstrate that in the model the anticyclones are little affected by remote heat sources. That is, the anticyclones are primarily a response to nearby thermal forcing in their respective hemispheres, and there is no indication that the NAMA is a downstream response to the Asian monsoon circulation.

\section{4) PARTitioning the Western HEMISPHERE HEATING}

Runs $2 \mathrm{a}-2 \mathrm{c}$ show that the NAMA is principally driven by latent heating in the Western Hemisphere. Runs 3a-3i are then used to determine the importance of heating in different longitude sectors and latitude zones within the Western Hemisphere. The heating is first partitioned into three $60^{\circ}$ longitude sectors (WH1, WH2, and WH3) as defined in Fig. 1. Figure 6 shows the longitudinalmean precipitation in these three sectors. One Eastern 
a) ERA-Interim

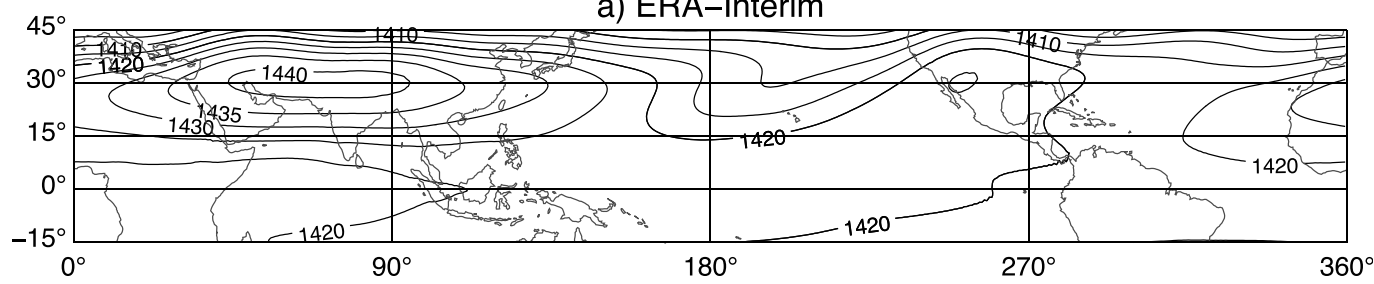

b) Run 2a (EH heating + WH heating)

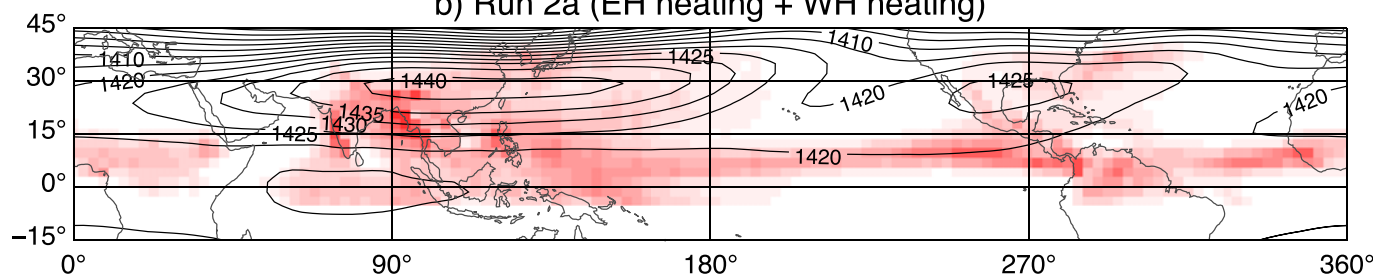

c) Run $2 b$ (EH heating only)

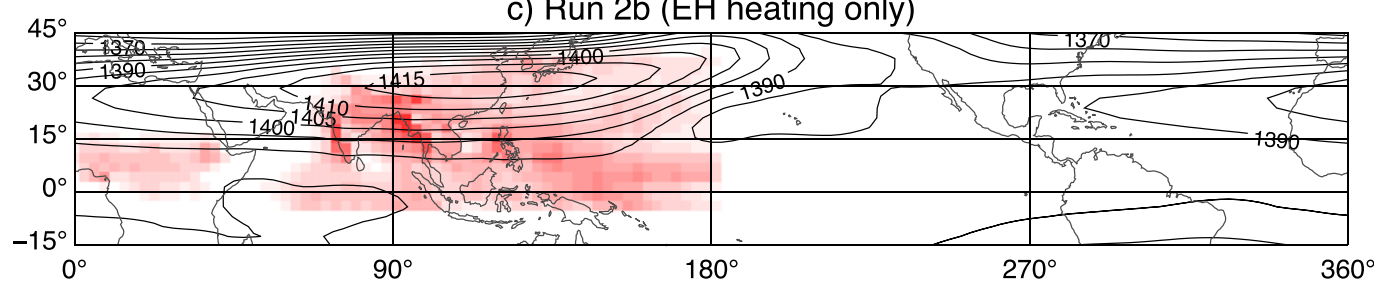

d) Run 2c (WH heating only)

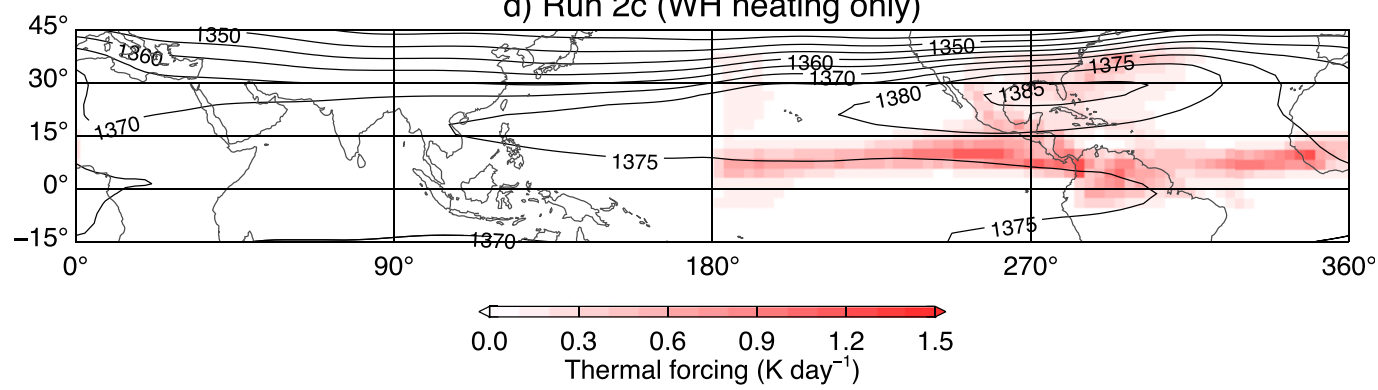

FIG. 4. (a) ERA-Interim climatological July geopotential height $Z$. (b)-(d) Time-mean CAM $Z$ (contours) for runs $2 \mathrm{a}-2 \mathrm{c}$, respectively, with geographical distributions of TMPA-derived thermal forcing $Q_{\mathrm{LH}}$ (color). Both fields indicate values at $150 \mathrm{hPa}$. Contour interval of $Z$ is $5 \mathrm{dam}$. The horizontal distribution of $Q_{\mathrm{LH}}$ is specified in Table 2. The model has no topography or land-ocean contrast, and the continents are shown only to provide a geographic reference.

Hemisphere sector (EH1) is shown for comparison. The maximum $\mathrm{WH}$ and $\mathrm{EH}$ precipitation rates are similar, but the WH sectors are dominated by the narrow ITCZ precipitation located between $0^{\circ}$ and $15^{\circ} \mathrm{N}$, while EH1 has a large amount of precipitation between about $10^{\circ}$ and $40^{\circ} \mathrm{N}$. There is little subtropical precipitation in WH1 and WH3 (less than $1 \mathrm{~mm} \mathrm{day}^{-1}$ ), but there is a substantial amount of precipitation poleward of $15^{\circ} \mathrm{N}$ in the middle sector (WH2).

Results for the three WH sectors simulations (runs $3 a-3 c)$ are shown in Figs. 7a-c. Note that the latitudinal extent of the heating is limited to be between $5^{\circ} \mathrm{S}$ and $40^{\circ} \mathrm{N}$. The total heating in run $3 \mathrm{~b}$ (middle sector) comprises $\sim 51 \%$ of the total Western Hemisphere heating in run $2 c$ (Table 2), and it has substantially more precipitation in the subtropics than the other two runs. For runs $3 a$ and $3 c$, which have heating primarily within the Pacific and Atlantic ITCZs, respectively, the subtropical response is weak. Run $3 \mathrm{~b}$, however, produces a substantial anticyclone in the subtropics.

To investigate the relative importance of the magnitude of the heating and its meridional distribution, each longitude sector is divided at $15^{\circ} \mathrm{N}$ into tropical and subtropical latitude zones, giving six regions. Experiments $3 \mathrm{~d}-3 \mathrm{i}$ are carried out using heating from those individual regions. Runs $3 \mathrm{~d}$ and $3 \mathrm{f}$ (not shown), which include only the tropical part of the heating from runs $3 \mathrm{a}$ and $3 \mathrm{c}$, produce weak anticyclones similar to Figs. 7a and 7c. Similarly, runs $3 \mathrm{~g}$ and $3 \mathrm{i}$, which have only a small amount of heating in the subtropics, 

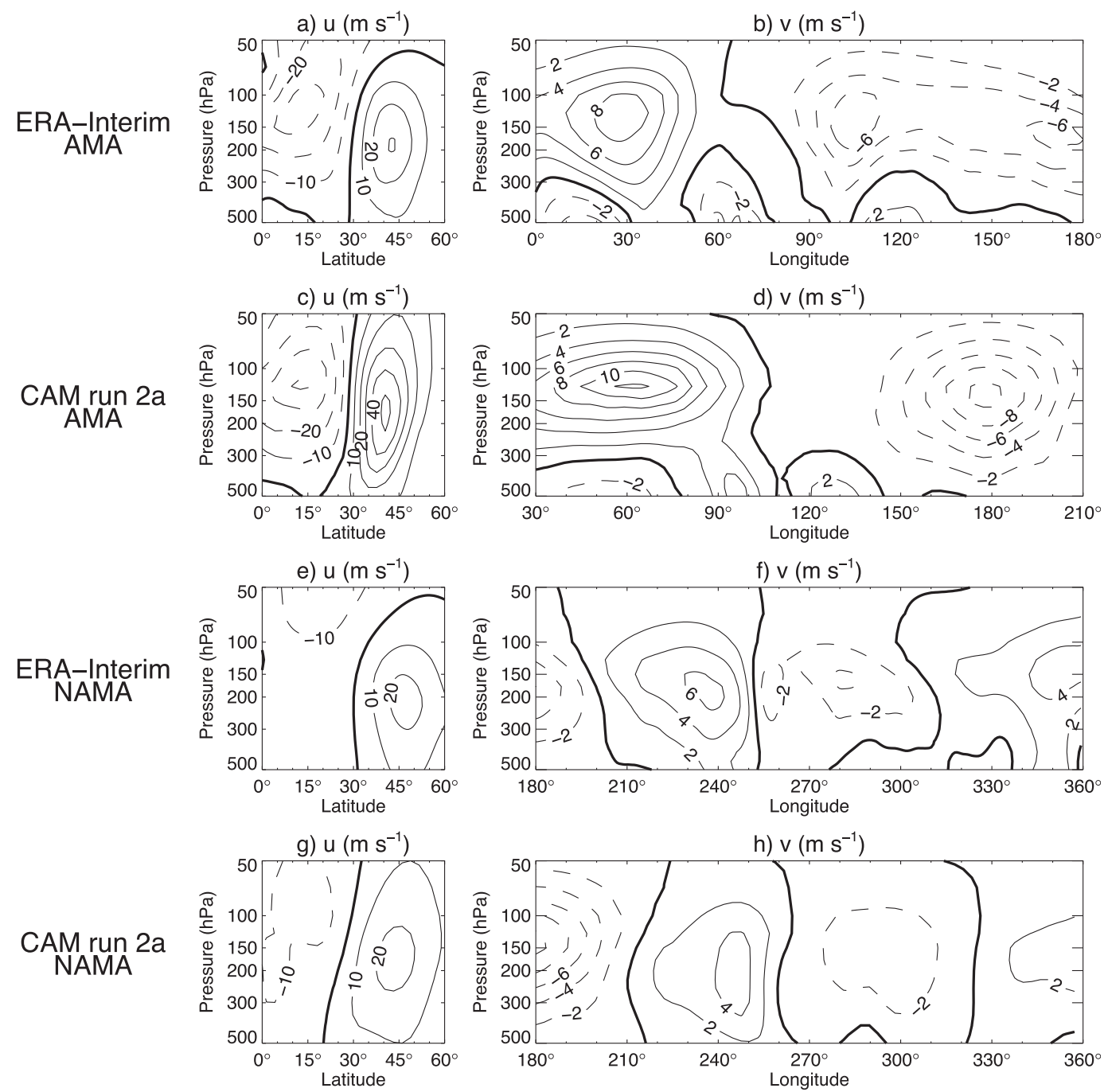

FIG. 5. (left) Latitude-pressure cross sections of time-mean, longitudinal-mean zonal velocity $u$. (right) Longitude-pressure cross sections of time-mean, latitudinal-mean meridional velocity $v$. Only cross sections between 500 and $50 \mathrm{hPa}$ are shown. Note that the longitude (latitude) ranges of observations and model used for averaging $u(v)$ are different but the extents of longitude $\left(\Delta \lambda=45^{\circ}\right)$ and latitude $\left(\Delta \phi=10^{\circ}\right)$ are the same. Note also that the longitude range of (d) is shifted $30^{\circ}$ eastward for better correspondence with observations. (a),(b) ERAInterim climatological July $u\left(0^{\circ}-60^{\circ} \mathrm{N}, 45^{\circ}-90^{\circ} \mathrm{E}\right)$ and $v\left(25^{\circ}-35^{\circ} \mathrm{N}, 0^{\circ}-180^{\circ} \mathrm{E}\right)$. (c),(d) $\mathrm{CAM} u\left(0^{\circ}-60^{\circ} \mathrm{N}, 90^{\circ}-135^{\circ} \mathrm{E}\right)$ and $v\left(20^{\circ}-30^{\circ} \mathrm{N}, 30^{\circ} \mathrm{E}-150^{\circ} \mathrm{W}\right)$. (e),(f) ERA-Interim climatological July $u\left(0^{\circ}-60^{\circ} \mathrm{N}, 120^{\circ}-75^{\circ} \mathrm{W}\right)$ and $v\left(25^{\circ}-35^{\circ} \mathrm{N}\right.$, $\left.180^{\circ} \mathrm{W}-0^{\circ}\right)$. (g), (h) CAM $u\left(0^{\circ}-60^{\circ} \mathrm{N}, 120^{\circ}-75^{\circ} \mathrm{W}\right)$ and $v\left(20^{\circ}-30^{\circ} \mathrm{N}, 180^{\circ} \mathrm{W}-0^{\circ}\right)$. Contour intervals of $u$ and $v$ are 10 and $2 \mathrm{~m} \mathrm{~s}^{-1}$, respectively (solid for positive values, dashed for negative values, and bold for zero).

produce weak anticyclones (not shown). In the middle sector, however, both runs $3 \mathrm{e}$ (tropical heating) and $3 \mathrm{~h}$ (subtropical heating) produce a subtropical anticyclone (Figs. $7 \mathrm{~d}$ and $7 \mathrm{e}$ ), with a much stronger response coming from the latter case. Note that although the response from the subtropical heating is larger, the total heating in the subtropical sector is only $\sim 62 \%$ of the tropical sector (Table 2). These two simulations suggest that the latitude of the heating plays a significant role in determining the strength of the anticyclone.
We note that precipitation over Mexico and the southern United States, along with the NAMA response in the UTLS, exhibits a northward propagation during late spring and early summer (Higgins et al. 1999). Run $3 e$ resembles the early stage of the NAMA, with a weak anticyclone at a low latitude, while runs $3 \mathrm{~b}$ and $3 \mathrm{~h}$, which are very similar, can be viewed as the mature stage of the NAMA. A closer look at the geographical distribution of the heating in these simulations suggests that the onset of the North American monsoon precipitation across different regions is intimately related 


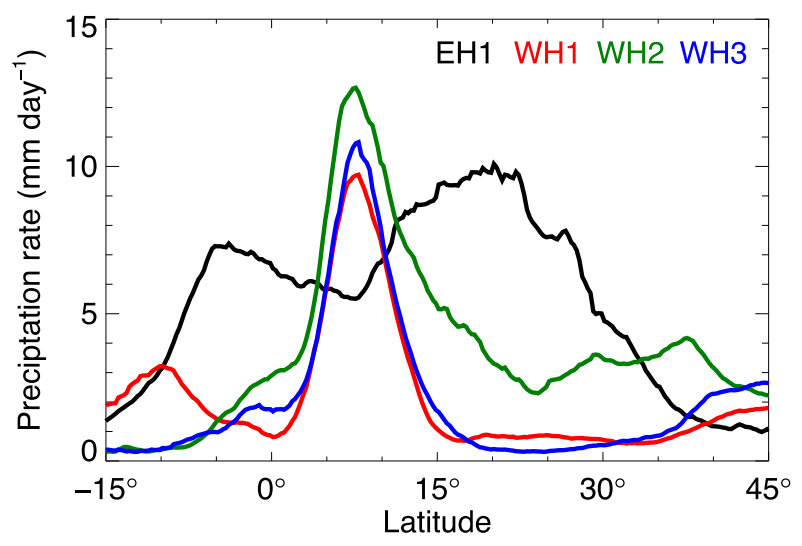

FIG. 6. TMPA longitudinal-mean climatological July precipitation rate $R$ of sectors EH1, WH1, WH2, and WH3, as defined in Fig. 1.

to the northward propagation and development of the NAMA.

\section{b. Response to the idealized forcing}

\section{1) ZonALly ELONGATED HEATING}

Although all three WH sectors have substantial precipitation in the deep tropics, only the heating in $\mathrm{WH} 2$, which also has substantial precipitation in the subtropics, produces a significant subtropical response. Experiments $3 \mathrm{e}$ and $3 \mathrm{~h}$ show that, despite the large magnitude of forcing, the response to the tropical precipitation in $\mathrm{WH} 2$ is small, and the anticyclone in run $2 \mathrm{c}$ is produced primarily by subtropical heating. The preliminary experiments and these realistic forcing experiments suggest that the magnitude and latitude of the forcing are both important for controlling the strength of anticyclones, which supports the Gill-type response, (1). To explore this question in a simpler context, we use two different idealized horizontal distributions, as described in section 3.

The experiments in this section (group 4) investigate the role of the latitude of the heating in the atmospheric response using idealized zonally elongated heating distributions. The total amount of heating is the same at all latitudes to isolate its effect in (1). The meridional profile of the heating is given by (6), with the meridional extent $\Delta \phi$ set to $15^{\circ}$, which is comparable to the narrow extent of the ITCZ in the three WH sectors as seen in Fig. 6.

Runs $4 \mathrm{a}-4 \mathrm{e}$ use a global zonally symmetric heating distribution centered at different latitudes. As expected, zonally symmetric forcing does not produce a localized anticyclone, even if the forcing is located in the subtropics, so no results from these experiments are shown here.

Runs $4 \mathrm{f}-4 \mathrm{j}$ restrict the zonally elongated heating to a $180^{\circ}$ longitude sector centered at $90^{\circ} \mathrm{W}\left(\Delta \lambda=180^{\circ}\right.$ and $\lambda_{0}=90^{\circ} \mathrm{W}$ ), with the center latitude $\phi_{0}$ ranging from $0^{\circ}$ to $30^{\circ} \mathrm{N}$ in $7.5^{\circ}$ increments (Table 3 ). The total amount of the heating is $25 \times 10^{19} \mathrm{~J} \mathrm{day}^{-1}$, which is similar to the total amount of the tropical part between $0^{\circ}$ and $15^{\circ} \mathrm{N}$ of the Western Hemisphere heating in run $2 \mathrm{c}$ (or the sum of the tropical heating between $0^{\circ}$ and $15^{\circ} \mathrm{N}$ in runs $3 \mathrm{~d}-3 \mathrm{f})$. The magnitude of the thermal forcing is adjusted in each run to keep the total amount of heating constant.

Figure 8 shows the results from experiments $4 \mathrm{~g}$ and 4 i. The quantity displayed is the zonally asymmetric part of the atmospheric response $Z^{*}=Z-[Z]$, where $Z$ is the time-mean geopotential height at $150 \mathrm{hPa}$ and square brackets indicate the zonal average of $Z$. The magnitude of the anticyclone $Z_{\max }^{*}$ is defined as the maximum value of $Z^{*}$ outside the tropics. Run $4 \mathrm{~g}$ in Fig. 8a, with $\phi_{0}=7.5^{\circ} \mathrm{N}$, resembles the ITCZ precipitation in Fig. 6. The response to this forcing in the subtropics and extratropics is weak. The response in the equatorial channel is even weaker. When the heating is centered at the equator, the responses are fairly similar although the equatorial channel response to the east of the forcing is slightly stronger (not shown). Differences of the responses between run $4 \mathrm{~g}$ and Gill's solution can be attributed to differences in the basic state and in the shape of the heating distribution. The heating in Gill's model has a larger meridional extent than the heating in run $4 \mathrm{~g}$. Here, narrow heating confined to the deep tropics leads to a smaller meridional velocity because of the weaker Coriolis effect and vortex stretching mechanism at lower latitudes (cf. Fig. 3 of Phlips and Gill 1987). The responses in the tropics and subtropics are still weak when the heating moves to $\phi_{0}=15^{\circ} \mathrm{N}$ (not shown). The extratropical response becomes distinct when the heating moves to $\phi_{0}=22.5^{\circ} \mathrm{N}$ in run $4 \mathrm{i}$ (Fig. 8b). A very zonally elongated anticyclone covers the whole Western Hemisphere. The response is similar to run $4 \mathrm{i}$ when the heating moves to $\phi_{0}=30^{\circ} \mathrm{N}$ (not shown).

\section{2) Compact Regional heAting}

Because narrow and zonally elongated heating in the deep tropics produces little response in the subtropics, we next consider the response to more compact regional heating. For this we use the idealized heating distribution given by (7) with a zonal extent $\Delta \lambda$ of $60^{\circ}$ and a meridional extent $\Delta \phi$ of $30^{\circ}$. The meridional extent is set to roughly match the extent of the precipitation if the ITCZ peak is subtracted from the profile in $\mathrm{WH} 2$ (Fig. 6). Runs 5a-5e examine the effect of the latitude of the heat source by varying the center latitude $\phi_{0}$ from $0^{\circ}$ to $20^{\circ} \mathrm{N}$ in $5^{\circ}$ increments (Table 3 ). The total amount of the heating is $6 \times 10^{19} \mathrm{~J} \mathrm{day}^{-1}$, which is less 

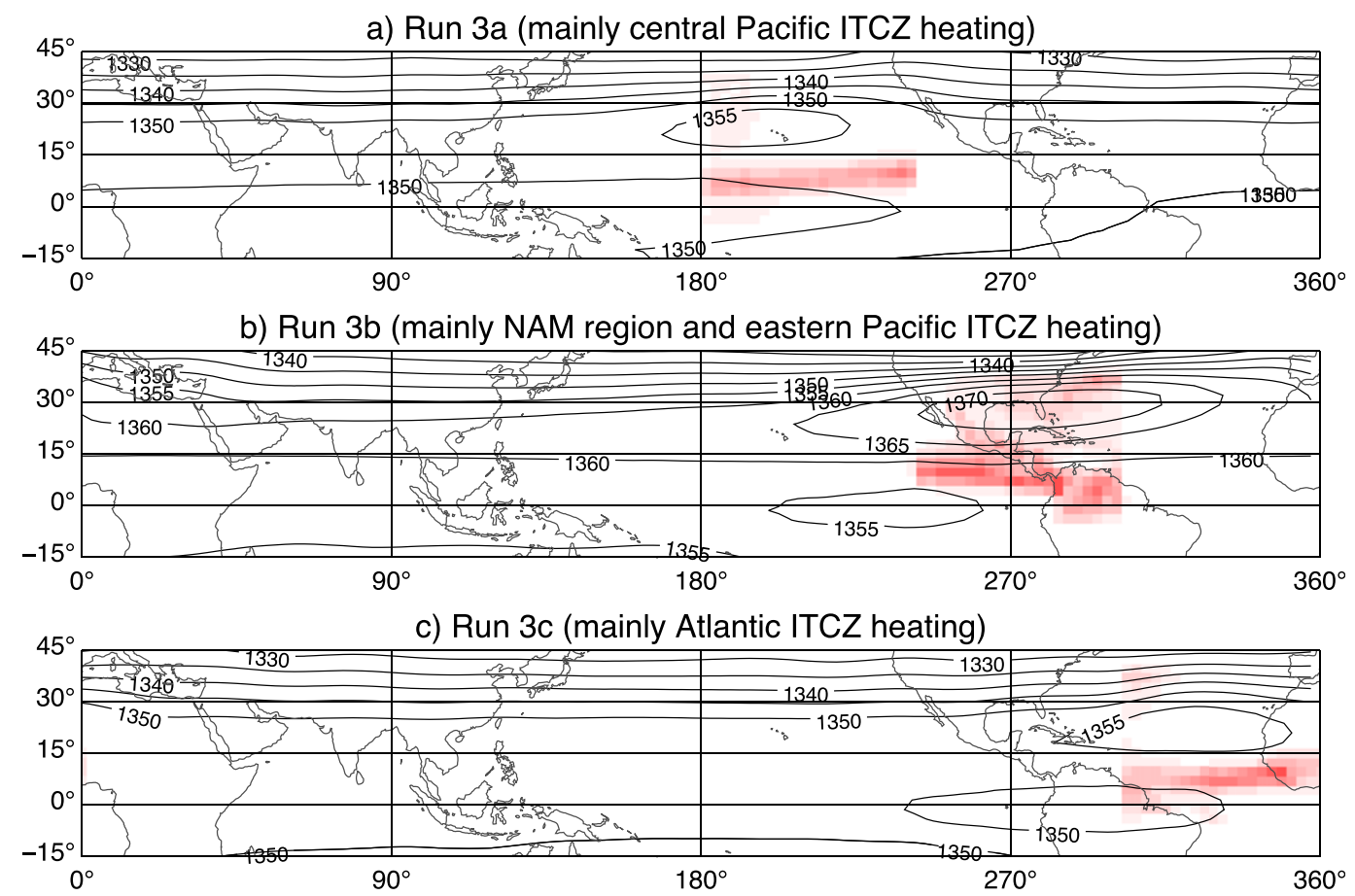

d) Run $3 e$ (tropical part of heating of run $3 b$ )
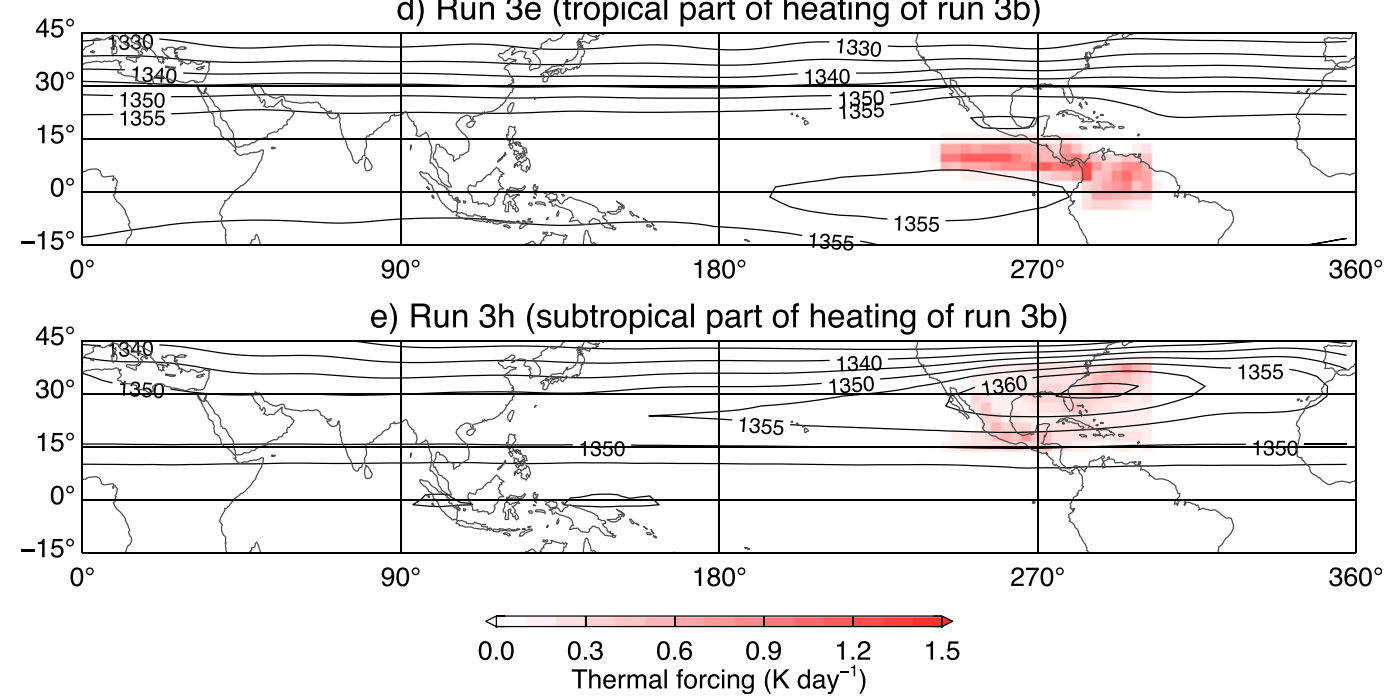

FIG. 7. As in Fig. 4, but for runs 3a-3c, 3e, and $3 \mathrm{~h}$.

than one quarter of the zonally elongated heating in the previous subsection. The magnitude of heating is chosen so that the sum of the regional heating from runs $5 \mathrm{a}-5 \mathrm{e}$ and the zonally elongated heating from runs $4 \mathrm{f}-4 \mathrm{j}$ is close to the total amount of Western Hemisphere heating between $0^{\circ}$ and $30^{\circ} \mathrm{N}$ in run $2 \mathrm{c}$. Run $5 \mathrm{~d}\left(\phi_{0}=15^{\circ} \mathrm{N}\right)$ resembles the regional precipitation in $\mathrm{WH} 2$; run $5 \mathrm{e}\left(\phi_{0}=20^{\circ} \mathrm{N}\right)$ better matches the geographic distribution, while underrepresenting the magnitude of the precipitation in the Asian sector EH1 (Fig. 6).
Figure 9 shows the eddy response $Z^{*}$ to the regional heating at different latitudes. Forcing at the equator (run 5a), excites weak extratropical responses to the north (Fig. 9a). As the forcing is shifted poleward, the responses in the tropical channel to the west and in the extratropics strengthen somewhat (Fig. 9b). For $\phi_{0}$ between $10^{\circ}$ and $20^{\circ} \mathrm{N}$ (Figs. 9c-e), the forcing produces a response in both tropics and subtropics, resulting in a quadrupole structure with anomalous westerlies east of the heat source and easterlies west of the heat source. The locations of the NAMA in runs $5 c-5 e$ are 

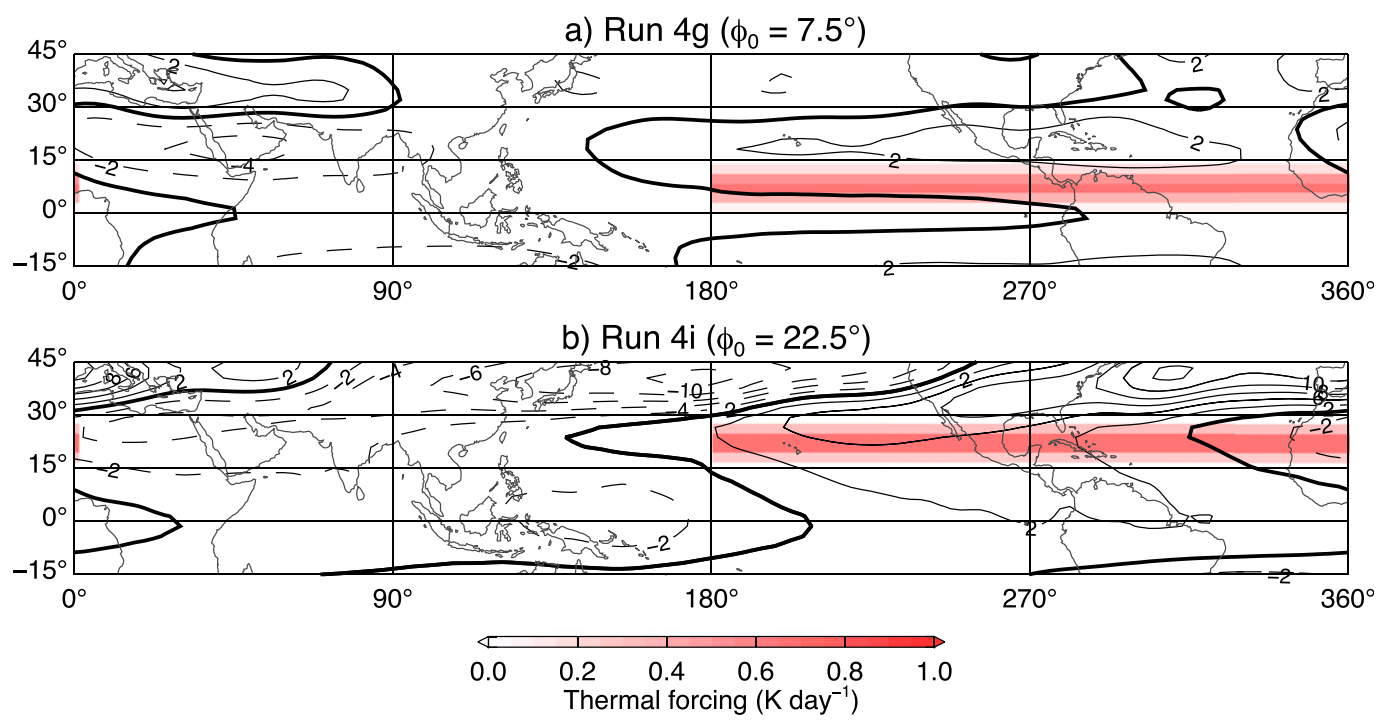

FIG. 8. Time-mean geopotential height anomaly $Z^{*}$ (contours) and geographical distributions of zonally elongated heating $Q_{\mathrm{LH}}$ (color) for runs (a) $4 \mathrm{~g}$ and (b) $4 \mathrm{i}$. Both fields indicate values at $150 \mathrm{hPa}$. Contour interval of $Z^{*}$ is 2 dam (solid for positive values, dashed for negative values, and bold for zero). Note the change of the color-bar scale from Figs. 4 and 7.

similar to run $3 \mathrm{~b}$ (Figs. 9c-e), while the maximum response to the regional forcing increases substantially as $\phi_{0}$ moves from $15^{\circ}$ to $20^{\circ} \mathrm{N}$. With a constant amount of latent heating, experiment 5 shows that the response strengthens as the heating moves poleward and $f$ increases. This suggests that the AMA is stronger than the NAMA because of both the larger amount of latent heating in the Eastern Hemisphere (Fig. 6) and the more poleward position of the intense heating outside the deep tropics (Fig. 9e).

Compared to the zonally elongated forcing experiments, a distinct extratropical response appears for a lower $\phi_{0}$ with the compact forcing. Because the meridional extent of the compact heating is wider $\left(30^{\circ}\right.$ vs $\left.15^{\circ}\right)$, the heating has an effect in the subtropics while the center is still in the deep tropics. Figures 8 and 9 show that when the length of the forcing region decreases, the zonal extent of the extratropical response also decreases. For example, other than the elongated anticyclone, a wavenumber- 1 response is clearly seen in the Eastern Hemisphere because of the $180^{\circ}$ longitude heating (Fig. 8b). It suggests that similar zonal scales of the heating region produce similar zonal extents of the extratropical response. It implies that the AMA covers a much larger area than the NAMA because the zonal extent of the precipitation region in the subtropics of the Eastern Hemisphere is much larger than the analogous zonal extent in the Western Hemisphere (Fig. 1).

Experiments 1-6 use T42L30 resolution. It has been reported that increasing the number of vertical levels could improve the simulation of Asian monsoon in the UTLS region in the comprehensive version of the CESM (Wang et al. 2018). To test the sensitivity of the model to changes in both horizontal and vertical resolution, additional runs were carried out with higher horizontal resolution (runs 7a-7e at T85L30) and higher vertical resolution (runs $7 \mathrm{f}-7 \mathrm{j}$ at T42L60). In both cases the results do not change significantly from the T42L30 runs (not shown).

\section{3) LINEARITY OF THE RESPONSE}

The linearity of the atmospheric response is evaluated by repeating runs $5 \mathrm{a}-5 \mathrm{e}$ with the heating scaled by factors of 0.5 (runs $6 \mathrm{a}-6 \mathrm{e}$ ) and 2 (runs $6 \mathrm{f}-6 \mathrm{j}$ ). Details of the numerical experiments are given in Table 3. Figure 10a shows the strength of the anticyclone as a function of the total amount of forcing $Q_{\text {total }}$ relative to experiment 5. The strength of the response is measured by the maximum geopotential height anomaly $Z_{\max }^{*}$ of the anticyclone. We fit the data points for each center latitude of forcing $\phi_{0}$ using a linear least squares fit with the intercept forced to be zero. For a fixed value of $\phi_{0}$, the amplitude of the response varies nearly linearly in relation to the magnitude of the heating within the range of heating values examined.

Figure 10b shows the strength of the anticyclone as a function of $\phi_{0}$ for the same three sets of experiments. When the forcing is close to the equator, the response is weak. As the forcing shifts poleward, the response 
a) Run $5 a\left(\phi_{0}=0^{\circ}\right)$

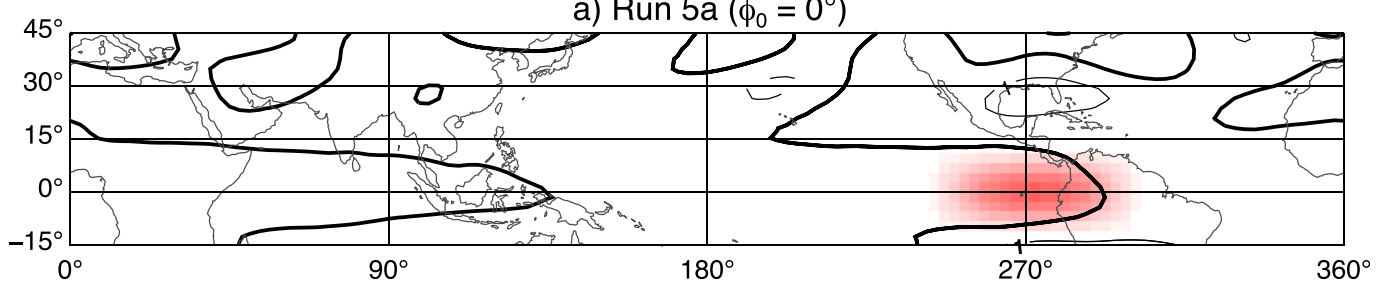

b) Run $5 b\left(\phi_{0}=5^{\circ}\right)$

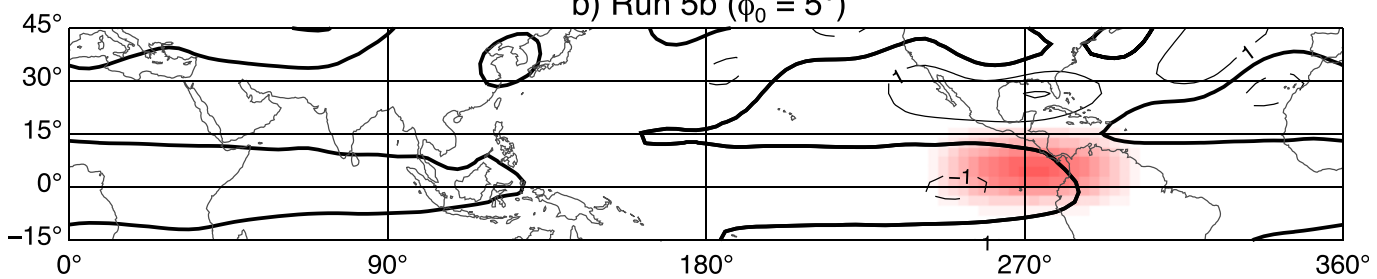

c) Run $5 \mathrm{c}\left(\phi_{0}=10^{\circ}\right)$

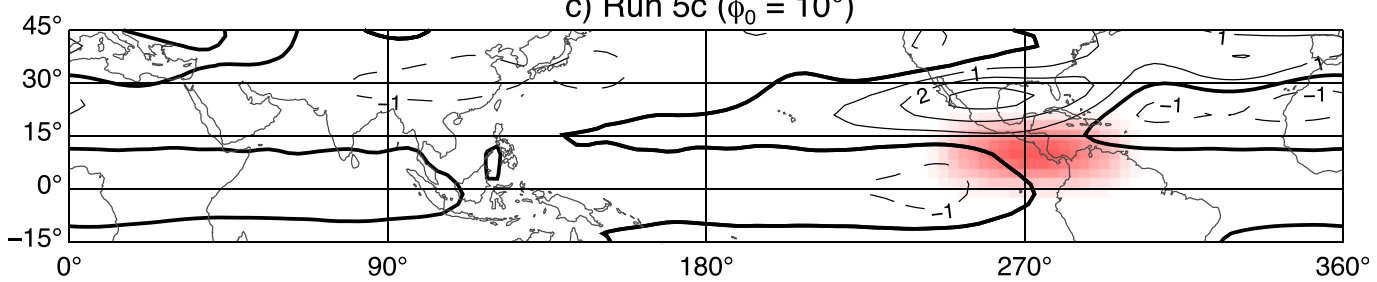

d) Run $5 d\left(\phi_{0}=15^{\circ}\right)$

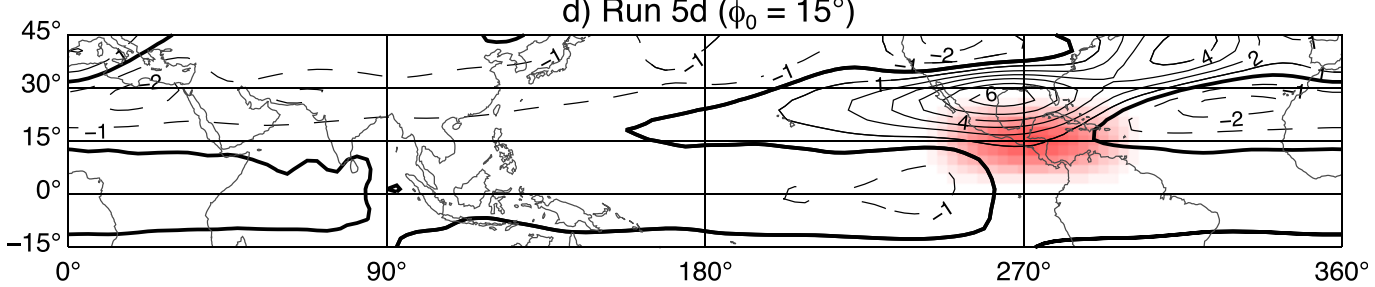

e) Run $5 e\left(\phi_{0}=20^{\circ}\right)$

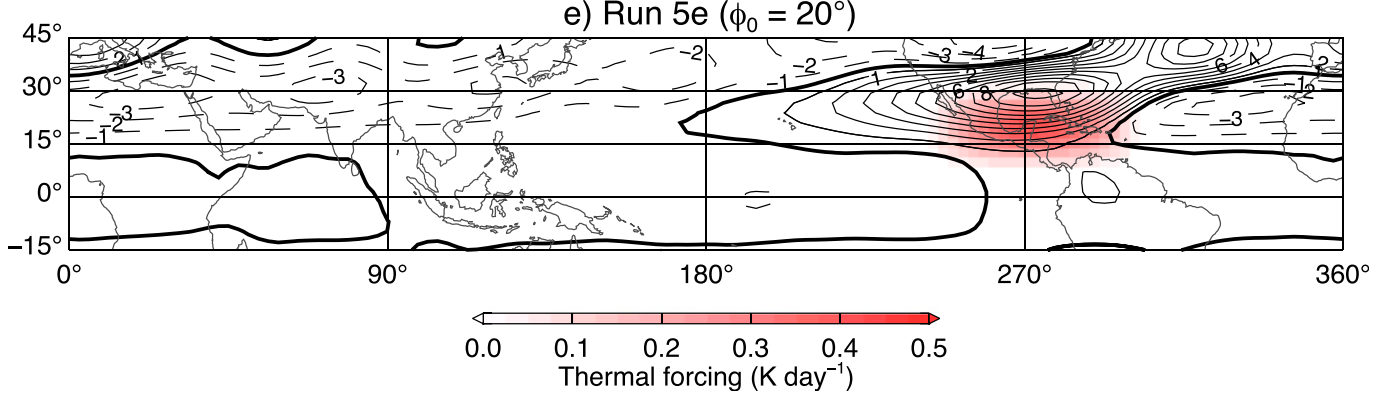

FIG. 9. As in Fig. 8, but for runs (a) 5a-(e) 5e with the geographical distributions of compacted regional heating $Q_{\mathrm{LH}}$ (color). Contour interval of $Z^{*}$ is $1 \mathrm{dam}$ (solid for positive values, dashed for negative values, and bold for zero). Note the change of the color-bar scale from Figs. 4, 7, and 8.

increases somewhat nonlinearly as a function of latitude. This could be in part a result of the nonlinear meridional profile of the heating. That is, the amount of heating in the subtropics increases nonlinearly as the center of the heating shifts poleward. If, however, the atmospheric response is plotted as a function of the total heating poleward of $15^{\circ} \mathrm{N}$ rather than $\phi_{0}$ (not shown), the response remains nonlinear. This suggests that the nonlinearity of the response is not simply a result of the nonlinear meridional profile of the heating in (7).

\section{Conclusions}

The origin and dynamics of the upper-tropospheric North American monsoon anticyclone are investigated through numerical experiments with an idealized general circulation model and comparisons with 

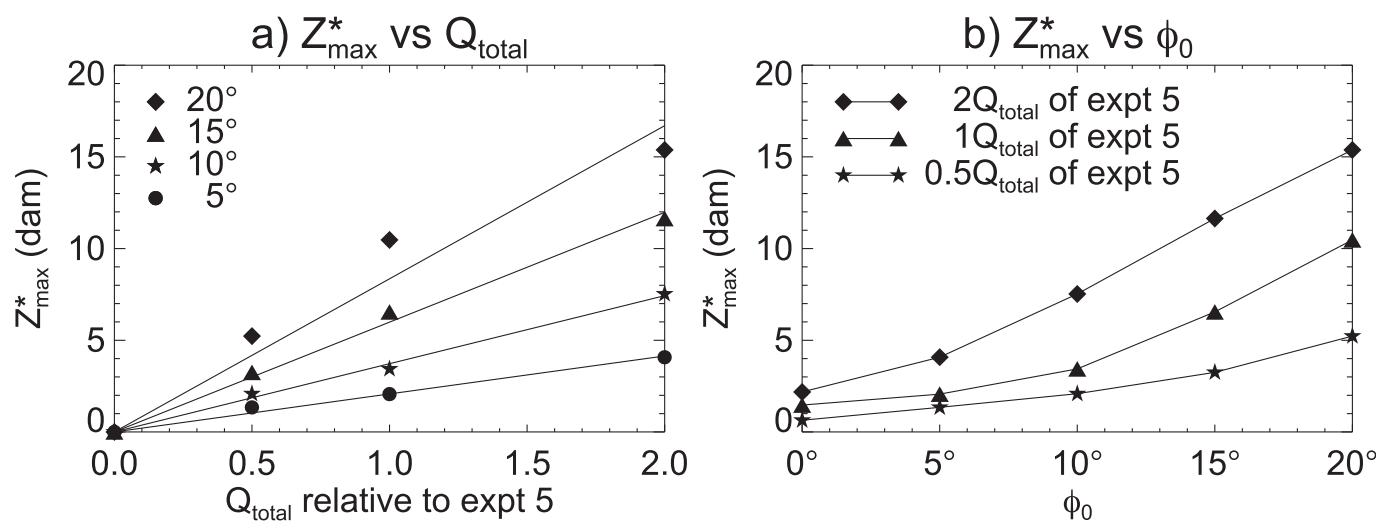

FIG. 10. (a) Linear least squares fits of maximum time-mean geopotential height anomaly $Z_{\max }^{*}$ at $150 \mathrm{hPa}$ with the intercept forced to be zero as a function of the total amount of heating $Q_{\text {total }}$ relative to experiment 5 for selected center latitudes of the heating $\phi_{0}$. (b) $Z_{\max }^{*}$ as a function of $\phi_{0}$ for runs $5 \mathrm{a}-5 \mathrm{e}, 6 \mathrm{a}-6 \mathrm{e}\left(0.5 Q_{\mathrm{total}}\right.$ of experiment 5), and $6 \mathrm{f}-6 \mathrm{j}\left(2 Q_{\text {total }}\right.$ of experiment 5). Scalings of $Q_{\text {total }}$ are labeled (see also Table 3$)$.

observational analyses. The analysis focuses on the time-averaged response of the atmosphere. The model uses a simplified physics package based on HS94 that relaxes the temperature to a prescribed zonally symmetric basic state. To simulate a more realistic tropical circulation, the physical parameterizations and basic state are modified somewhat from HS94 according to SW06, and an explicit dry convection scheme is included. The model is forced by a steady diabatic heat source based on TMPA precipitation data or prescribed from idealized heating distributions. Significant approximations in the idealized model include the absence of topography, land-sea contrast, and temporal variations of the forcing. These effects are partially compensated by adjusting the magnitude of the thermal forcing. The model uses a constant vertical heating profile throughout the region where heating is applied and ignores heating outside of the tropics and Northern Hemisphere subtropics. Experiments with increased horizontal and vertical resolution (T85L30 and T42L60) show that the simulations are not sensitive to either horizontal or vertical resolution.

The model is first tuned to give a realistic representation of the boreal summer upper-tropospheric circulation, including the AMA, NAMA, and the mid-Pacific trough, using a realistic geographical distribution of diabatic heating based on the observed TMPA timemean precipitation. To produce a realistic zonal-mean circulation, the latent heating is scaled to $59 \%$ of its observed value. This heating distribution is partitioned geographically in various ways, and the response to each individual region is examined. When the heating is turned off in either the Eastern or Western Hemisphere, the anticyclone in that hemisphere disappears, while the anticyclonic circulation in the other hemisphere slightly weakens. This demonstrates that the AMA and NAMA are fundamentally responses to diabatic heating within their respective hemispheres, and the NAMA in particular is not a downstream wave response to Asian monsoonal heating. During the warm season the majority of the precipitation in the Western Hemisphere falls in a narrow zone between about $5^{\circ}$ and $15^{\circ} \mathrm{N}$ within the Atlantic and Pacific ITCZs and across the northern part of South America. The NAMA, however, is primarily a response to heating poleward of $15^{\circ} \mathrm{N}$ in the longitude sector between $60^{\circ}$ and $120^{\circ} \mathrm{W}$, which includes the northern part of Central America, Mexico, the southern United States, the Caribbean Sea, and the Gulf of Mexico. This demonstrates the importance of the latitude of the heating to the response.

To explore the atmospheric response to the shape and location of the heating, the model is forced with idealized heating distributions that represent either zonally elongated (ITCZ-like) or compact regional precipitation features. When the zonally elongated heating is placed near the equator, the response in the extratropics is weak. The extratropical response is significant only when the heating is located outside the deep tropics. The response to a compact heating distribution depends on the latitude of the heating as well. An extratropical response is evident when the heating is centered poleward of $10^{\circ} \mathrm{N}$, and the extent of the response is more localized compared to the zonally elongated forcing. These experiments support the conclusion that the AMA is stronger than the NAMA is because of both the heavier precipitation in the Eastern Hemisphere and the location of the intense precipitation at higher latitudes over Asia compared to North America. 
Compared to the zonally elongated heating, the compact heating is shorter in the zonal direction and wider in the meridional direction. The numerical experiments indicate that the longitudinal extent of the AMA is much larger than the NAMA is in part because the zonal extent of the subtropical precipitation in the Eastern Hemisphere is greater than in the Western Hemisphere.

The linearity of the atmospheric response of the idealized forcing experiments is examined by varying the magnitude of the heating. To a good approximation the strength of the anticyclone is linearly proportional to the magnitude of the applied heating, but for a fixed magnitude of heating the response depends nonlinearly on the latitude of the heating.

The model results support the idea that the AMA and NAMA are largely independent of one another, being forced primarily by diabatic heating in their respective hemispheres. That is, both anticyclones are MatsunoGill-type responses. The differences in the amplitude and zonal extent of the AMA and NAMA are due in part to the total amount and zonal distribution of heating in each hemisphere, but are primarily a result of the different meridional distributions of heating in the two hemispheres.

Acknowledgments. We are grateful to three anonymous reviewers for their constructive comments that helped improve the manuscript. We thank Andrew Dessler, Ramalingam Saravanan, and Courtney Schumacher for their comments on an earlier version of the manuscript. We thank the CESM working groups at the NCAR Climate and Global Dynamics (CGD) Laboratory for developing the model. We particularly thank Isla Simpson for providing developer's access of CAM and assistance with running the model. The version of CAM 5.4 in this study was made available through the Simpler Models Initiative as part of the CESM project; this initiative is supported by NCAR under the sponsorship of the National Science Foundation (NSF) and the United States Department of Energy (DOE). This research is funded by NSF Grant AGS-1550611 to Texas A\&M University. Portions of this research were carried out with advanced computing resources provided by Texas A\&M High Performance Research Computing (HPRC), and we thank Ping Luo for setting up CAM on the Texas A\&M Ada system. We thank the ECMWF for producing the ERA-Interim product, which was obtained from the NCAR Research Data Archive. The TMPA data were obtained from the NASA Goddard Earth Sciences (GES) Data and Information Services Center (DISC). Outputs from the model simulations are available upon request.

\section{REFERENCES}

Adams, D. K., and A. C. Comrie, 1997: The North American monsoon. Bull. Amer. Meteor. Soc., 78, 2197-2213, https:// doi.org/10.1175/1520-0477(1997)078<2197:TNAM>2.0.CO;2.

Baker, H. S., T. Woollings, and C. Mbengue, 2017: Eddy-driven jet sensitivity to diabatic heating in an idealized GCM. J. Climate, 30, 6413-6431, https://doi.org/10.1175/JCLI-D-16-0864.1.

Barlow, M., S. Nigam, and E. H. Berbery, 1998: Evolution of the North American monsoon system. J. Climate, 11, 2238-2257, https://doi.org/10.1175/1520-0442(1998)011<2238: EOTNAM $>2.0 . \mathrm{CO} ; 2$.

Chao, W. C., and B. Chen, 2001: The origin of monsoons. J. Atmos. Sci., 58, 3497-3507, https://doi.org/10.1175/1520-0469(2001) 058<3497:TOOM $>2.0 . \mathrm{CO} ; 2$.

Chen, P., M. P. Hoerling, and R. M. Dole, 2001: The origin of the subtropical anticyclones. J. Atmos. Sci., 58, 18271835, https://doi.org/10.1175/1520-0469(2001)058<1827: TOOTSA $>2.0 . \mathrm{CO} ; 2$.

Chen, T.-C., 2003: Maintenance of summer monsoon circulations: A planetary-scale perspective. J. Climate, 16, 20222037, https://doi.org/10.1175/1520-0442(2003)016<2022: MOSMCA $>2.0 . \mathrm{CO} ; 2$.

Dee, D. P., and Coauthors, 2011: The ERA-Interim reanalysis: Configuration and performance of the data assimilation system. Quart. J. Roy. Meteor. Soc., 137, 553-597, https://doi.org/ 10.1002/qj.828.

DeMaria, M., 1985: Linear response of a stratified tropical atmosphere to convective forcing. J. Atmos. Sci., 42, 19441959, https://doi.org/10.1175/1520-0469(1985)042<1944: LROAST $>2.0 . \mathrm{CO} ; 2$.

Dethof, A., A. O'Neill, J. M. Slingo, and H. G. J. Smit, 1999: A mechanism for moistening the lower stratosphere involving the Asian summer monsoon. Quart. J. Roy. Meteor. Soc., 125, 1079-1106, https://doi.org/10.1002/qj.1999.49712555602.

Douglas, M. W., R. A. Maddox, K. Howard, and S. Reyes, 1993: The Mexican monsoon. J. Climate, 6, 1665-1677, https:// doi.org/10.1175/1520-0442(1993)006<1665:TMM>2.0.CO;2.

Dunkerton, T. J., 1995: Evidence of meridional motion in the summer lower stratosphere adjacent to monsoon regions. J. Geophys. Res., 100, 16 675-16 688, https://doi.org/10.1029/ 95JD01263.

ECMWF, 2009: ERA-Interim project. National Center for Atmospheric Research Computational and Information Systems Laboratory Research Data Archive, accessed 1 January 2017, https://doi.org/10.5065/D6CR5RD9.

Gadgil, S., 2003: The Indian monsoon and its variability. Annu. Rev. Earth Planet. Sci., 31, 429-467, https://doi.org/10.1146/ annurev.earth.31.100901.141251.

Gill, A. E., 1980: Some simple solutions for heat-induced tropical circulation. Quart. J. Roy. Meteor. Soc., 106, 447-462, https:// doi.org/10.1002/qj.49710644905.

, 1982: Atmosphere-Ocean Dynamics. Academic Press, 662 pp.

Held, I. M., and M. J. Suarez, 1994: A proposal for the intercomparison of the dynamical cores of atmospheric general circulation models. Bull. Amer. Meteor. Soc., 75, 1825-1830, https://doi.org/10.1175/ 1520-0477(1994)075<1825:APFTIO>2.0.CO;2.

Higgins, R. W., Y. Yao, and X. L. Wang, 1997: Influence of the North American monsoon system on the U.S. summer precipitation regime. J. Climate, 10, 2600-2622, https://doi.org/ 10.1175/1520-0442(1997)010<2600:IOTNAM>2.0.CO;2.

, K. C. Mo, and Y. Yao, 1998: Interannual variability of the U.S. summer precipitation regime with emphasis on the southwestern 
monsoon. J. Climate, 11, 2582-2606, https://doi.org/10.1175/ 1520-0442(1998)011<2582:IVOTUS>2.0.CO;2.

_, Y. Chen, and A. V. Douglas, 1999: Interannual variability of the North American warm season precipitation regime. J. Climate, 12, 653-680, https://doi.org/10.1175/1520-0442(1999) 012<0653:IVOTNA $>2.0$. CO;2.

Holton, J. R., 2004: An Introduction to Dynamic Meteorology. 4th ed. Academic Press, 535 pp.

Hoskins, B. J., and M. J. Rodwell, 1995: A model of the Asian summer monsoon. Part I: The global scale. J. Atmos. Sci., 52, 1329-1340, https://doi.org/10.1175/1520-0469(1995)052<1329: AMOTAS $>2.0 . \mathrm{CO} ; 2$.

Huffman, G. J., and D. T. Bolvin, 2017: TRMM and other data precipitation data set documentation. NASA Rep., 45 pp., ftp://meso.gsfc.nasa.gov/pub/trmmdocs/3B42_3B43_doc.pdf.

—_, and Coauthors, 2007: The TRMM Multisatellite Precipitation Analysis (TMPA): Quasi-global, multiyear, combinedsensor precipitation estimates at fine scales. J. Hydrometeor., 8, 38-55, https://doi.org/10.1175/JHM560.1.

Jiang, X., and N.-C. Lau, 2008: Intraseasonal teleconnection between North American and western North Pacific monsoons with 20-day time scale. J. Climate, 21, 2664-2679, https:// doi.org/10.1175/2007JCLI2024.1.

Lenters, J. D., and K. H. Cook, 1997: On the origin of the Bolivian high and related circulation features of the South American climate. J. Atmos. Sci., 54, 656-678, https://doi.org/10.1175/ 1520-0469(1997)054<0656:OTOOTB >2.0.CO;2.

MacVean, M. K., 1983: The effects of horizontal diffusion on baroclinic development in a spectral model. Quart. J. Roy. Meteor. Soc., 109, 771-783, https://doi.org/10.1002/qj.49710946206.

Matsuno, T., 1966: Quasi-geostrophic motions in the equatorial area. J. Meteor. Soc. Japan, 44, 25-43, https://doi.org/10.2151/ jmsj1965.44.1_25.

Neale, R. B., and Coauthors, 2012: Description of the NCAR Community Atmosphere Model (CAM 5.0). National Center for Atmospheric Research Tech. Rep. NCAR/TN-486+STR, 274 pp.

Phlips, P. J., and A. E. Gill, 1987: An analytic model of the heatinduced tropical circulation in the presence of a mean wind. Quart. J. Roy. Meteor. Soc., 113, 213-236, https://doi.org/ 10.1002/qj.49711347513.

Schneider, T., 2004: The tropopause and the thermal stratification in the extratropics of a dry atmosphere. J. Atmos. Sci., 61, 1317-1340, https://doi.org/10.1175/1520-0469(2004)061<1317: TTATTS $>2.0 . \mathrm{CO} ; 2$.

— macroturbulence into critical states of weak nonlinear eddyeddy interactions. J. Atmos. Sci., 63, 1569-1586, https:// doi.org/10.1175/JAS3699.1.

, and S. Bordoni, 2008: Eddy-mediated regime transitions in the seasonal cycle of a Hadley circulation and implications for monsoon dynamics. J. Atmos. Sci., 65, 915-934, https://doi.org/ 10.1175/2007JAS2415.1.

Schumacher, C., R. A. Houze Jr., and I. Kraucunas, 2004: The tropical dynamical response to latent heating estimates derived from the TRMM Precipitation Radar. J. Atmos. Sci., 61, 1341-1358, https://doi.org/10.1175/1520-0469(2004)061<1341: TTDRTL $>2.0 . \mathrm{CO} ; 2$.

Stensrud, D. J., 2013: Upscale effects of deep convection during the North American monsoon. J. Atmos. Sci., 70, 2681-2695, https://doi.org/10.1175/JAS-D-13-063.1.

Tandon, N. F., L. M. Polvani, and S. M. Davis, 2011: The response of the tropospheric circulation to water vapor-like forcings in the stratosphere. J. Climate, 24, 5713-5720, https://doi.org/ 10.1175/JCLI-D-11-00069.1.

_ - E. P. Gerber, A. H. Sobel, and L. M. Polvani, 2013: Understanding Hadley cell expansion versus contraction: Insights from simplified models and implications for recent observations. J. Climate, 26, 4304-4321, https://doi.org/10.1175/ JCLI-D-12-00598.1.

Taschetto, A. S., R. J. Haarsma, A. S. Gupta, C. C. Ummenhofer, K. J. Hill, and M. H. England, 2010: Australian monsoon variability driven by a Gill-Matsuno-type response to central west Pacific warming. J. Climate, 23, 4717-4736, https:/ doi.org/10.1175/2010JCLI3474.1.

Tropical Rainfall Measuring Mission, 2011: TRMM (TMPA) rainfall estimate L3 3 hour 0.25 degree $\times 0.25$ degree, version 7. Goddard Earth Sciences Data and Information Services Center, accessed 1 January 2017, https://doi.org/10.5067/ TRMM/TMPA/3H/7.

Vallis, G. K., 2017: Atmospheric and Oceanic Fluid Dynamics: Fundamentals and Large-Scale Circulation. 2nd ed. Cambridge University Press, 946 pp.

Vera, C., and Coauthors, 2006: Toward a unified view of the American monsoon systems. J. Climate, 19, 4977-5000, https:// doi.org/10.1175/JCLI3896.1.

Wang, X., and Coauthors, 2018: The simulation of stratospheric water vapor over the Asian summer monsoon in CESM1(WACCM) models. J. Geophys. Res. Atmos., 123, 11377-11391, https:/ doi.org/10.1029/2018JD028971.

Webster, P. J., 1972: Response of the tropical atmosphere to local, steady forcing. Mon. Wea. Rev., 100, 518-541, https://doi.org/ 10.1175/1520-0493(1972)100<0518:ROTTAT>2.3.CO;2.

— , V. O. Magaña, T. N. Palmer, J. Shukla, R. A. Tomas, M. Yanai, and T. Yasunari, 1998: Monsoons: processes, predictability, and the prospects for prediction. J. Geophys. Res., 103, 14 451-14 510, https://doi.org/10.1029/97JC02719.

Yanai, M., S. Esbensen, and J.-H. Chu, 1973: Determination of bulk properties of tropical cloud clusters from large-scale heat and moisture budgets. J. Atmos. Sci., 30, 611-627, https://doi.org/ 10.1175/1520-0469(1973)030<0611:DOBPOT>2.0.CO;2. 